\title{
Alinhamento das atividades de pesquisa científica e tecnológica realizadas pelas IES federais de Minas Gerais e as diretrizes da Política Industrial, Tecnológica e de Comércio Exterior - PITCE
}

\section{Tulio Chiarini}

Instituto de Engenharia de Produção e Gestão da Universidade Federal de Itajubá

Karina Pereira Vieira

Centro de Desenvolvimento e Planejamento Regional da Universidade Federal de Minas Gerais

Recebido: 25/07/2010 Versão revisada (entregue): 14/03/2011 Aprovado: 29/03/2011

\section{RESUMO}

Discute-se, nesse trabalho, o possível alinhamento entre atividades de pesquisa científica e tecnológica realizadas por instituições de ensino superior - IES e as diretrizes das políticas públicas de ciência e tecnologia do país. Como forma de delimitar o campo de análise, sem comprometer o escopo do trabalho, optou-se pela avaliação das áreas de pesquisa das IES federais mineiras e sua convergência com a Política Industrial e de Comércio Exterior PITCE. Mais do que isso, defende-se como essencial a função das IES enquanto geradoras de conhecimento dentro de um Sistema de Inovação, bem como um estreitamento das relações universidade-Estado-empresa como propõe a "hélice tríplice".

Palavras-CHAVE | Universidades; Produção de Conhecimento; Áreas Estratégicas.

Códigos JEL | O14; O25; O30.

\footnotetext{
Os autores gostariam de agradecer às contribuições anônimas dos pareceristas da Revista Brasileira de Inovação, os quais fizeram uma avaliação criteriosa da primeira versão deste. A todos somos gratos e os eximimos de responsabilidades pelas imperfeições que eventualmente ainda possam persistir.
} 


\title{
Alignment of science and technology activities by Minas Gerais federal universities with the guidelines of PITCE - Industrial, Technology and Foreign Trade Policy
}

\begin{abstract}
It is argued in this paper the possible alignment between scientific activities and technological research carried out by universities and the guidelines of public policies on science and technology in Brazil. As a way of delimiting the field of analysis, without compromising the scope of this paper, we restricted our focus on the federal public universities in Minas Gerais State and we checked the possible convergence with the Industrial Policy and Foreign Trade (PITCE). More than that, it is argued as essential the function of universities as generators of knowledge within an innovation system and a closer university-industry-state relation should be pursued as proposed by the 'Triple helix'.
\end{abstract}

KeYwords | Universities; Knowledge Production; Strategic Areas.

JEL-Codes | O14; O25; O30.

\section{Introdução}

As instituições de ensino superior - IES são atores fundamentais no processo de desenvolvimento de novos conhecimentos, por meio de pesquisa básica, pesquisa aplicada, desenvolvimento e engenharia.

Chiarini et al. (2010; no prelo) apresentaram um retrato das universidades federais de Minas Gerais, a partir da abordagem neoschumpeteriana/evolucionária dos Sistemas de Inovação - SI. Dando sequência aos trabalhos desenvolvidos por esses autores, o presente artigo busca avançar no estudo sobre o papel das universidades federais no SI. Para tanto, segue-se o mesmo referencial teórico utilizado pelos autores citados. Considera-se como base de análise o papel não somente das universidades federais de Minas Gerais, mas também dos Institutos Federais 
de Educação, Ciência e Tecnologia (Ifets) na constituição do Sistema Mineiro de Inovação, especialmente no que se refere à sua congruência com certas áreas estratégicas ao desenvolvimento do país e com a fronteira tecnológica, a partir de um enfoque empírico-quantitativo.

Desta forma, discute-se o possível alinhamento entre atividades de pesquisa científica e tecnológica realizada por IES e as diretrizes das políticas públicas de ciência e tecnologia do país. Como forma de delimitar o campo de análise, sem comprometer o escopo do trabalho, optou-se pela avaliação das áreas de pesquisa das IES federais mineiras e sua convergência com a Política Industrial e de Comércio Exterior (PITCE). Mais do que isso, defende-se como essencial a função das IES enquanto geradoras de conhecimento dentro de um SI, bem como um estreitamento das relações universidade-Estado-empresa como propõe a "hélice tríplice".

Observando-se a distribuição das universidades federais, em território brasileiro, nota-se que Minas Gerais é a Unidade da Federação com o maior número de instituiçôes federais de ensino superior Assim, sob tal aspecto, conforme Chiarini et al. (2010), Minas Gerais é um Estado atípico e, portanto, merece ser examinado quanto à alocação de recursos e produção de conhecimento em suas universidades.

Em 2008, Minas Gerais concentrava 20\% das universidades federais do país, além reunir 10,36\% de todas as publicações de artigos nacionais e internacionais, ficando atrás somente do Rio Grande do Sul (10,65\%), Rio de Janeiro (11,72\%) e São Paulo (32,11\%).' Observa-se também que o Estado mineiro, no que se refere às grandes áreas de conhecimento, encontra-se sempre entre os quatro maiores produtores de produção bibliográfica.

Além disso, Minas Gerais encontra-se entre os principais Estados brasileiros com empresas inovadoras. Entre 2006 e 2008, das 41.262 empresas brasileiras que implementaram inovações de produtos e/ou processos (das quais 38.299 pertencem à indústria extrativa ou de transformação), 5.208 localizavam-se em território mineiro, atrás apenas de São Paulo, com 12.379 empresas inovadoras em produtos e/ou processos (PINTEC, 2010).

Com tamanha capacidade de geração de conhecimento via IES e com papel de destaque no setor produtivo/inovativo nacional, torna-se interessante investigar a possível complementaridade entre as pesquisas desenvolvidas pelas instituições

1 Dados a partir do Plano Tabular do Diretório de Grupos de Pesquisa do CNPq. Produção bibliográfica refere-se ao somatório das produções de pesquisadores e estudantes. Artigos referem-se a textos completos publicados em periódicos especializados (de circulação nacional e internacional). Não há dupla contagem nos quantitativos da produção, 
federais de ensino superior em Minas Gerais e as "opçōes estratégicas" e "atividades portadoras de futuro" definidas pela PITCE.

Tal investigação faz-se importante não apenas para mapear as áreas de conhecimento e pesquisa do Estado com maior número de universidades federais do país, mas também para verificar a possibilidade de ocorrência de janelas de oportunidades capazes de permitir uma entrada relativamente autônoma em novos paradigmas tecnológicos em suas fases iniciais (PEREZ; SOETE, 1988). Nesse ínterim, reconhece-se o papel estratégico de algumas áreas de conhecimento, para o posicionamento nesses novos paradigmas, sendo que políticas específicas devem ser (re)pensadas em prol do desenvolvimento.

É válido destacar que, ao se realizar tal investigação, sabe-se, de antemão, que nem todo tipo de pesquisa realizada pelas IES direciona-se para setores estratégicos definidos por políticas industriais e de desenvolvimento do país, como os da PITCE. De certo que não é intenção deste trabalho sugerir ou defender a exclusão de linhas de pesquisa que não se enquadrem nos setores prioritários das políticas industriais e científico-tecnológicas do país, pois entende-se que são importantes instrumentos de compreensão das dinâmicas regional, histórica, econômica e social.

A importância dada às pesquisas universitárias voltadas para áreas prioritárias ao desenvolvimento científico-tecnológico vai em linha com a temática dos SI e é corroborada pela experiência de países que incentivaram a formação acadêmica em ciência e tecnologia, como a Índia, onde, em meados dos anos 1950, foi introduzida a primeira política científica e tecnológica do país, com o objetivo de estimular a formação de pessoal qualificado neste campo, a partir da criação de instituiçōes públicas de ensino médio e universitário, com ênfase nas áreas de exatas (matemática e engenharia), que continuaram a se propagar nas décadas seguintes (PRATES; CINTRA, 2009).

No caso indiano, a existência de mão de obra qualificada e barata e o domínio da língua inglesa constituíram importantes vantagens competitivas, favorecendo a obtenção de ganhos de escala em setores altamente tecnológicos, como o do software. Tais aspectos, associados aos processos de concentração de empresas e especialização produtiva, amplamente incentivados pelo Estado, promoveram o desenvolvimento de um cluster competitivo (cujo centro é Bangalore). Grandes empresas públicas foram alocadas em Bangalore pelo governo e deveriam funcionar como incubadoras, promovendo a qualificação e o treinamento progressivo de engenheiros e técnicos em informação, e, dessa forma, contribuir para atração de empresas privadas com base neste pool de mão de obra altamente capacitada e relativamente barata que estava sendo formada (NADVI, 1995). 
Casos como o indiano podem inspirar a mobilização da política científicotecnológica brasileira, em especial no que tange à atuação estratégica das universidades públicas, principalmente as federais, que podem se inserir ativamente numa estratégia nacional para ciência e tecnologia.

Dito isto, a análise deste artigo encontra-se centrada nos principais setores definidos como estratégicos ao desenvolvimento brasileiro pela PITCE, iniciativa do governo federal, nascida em 2003 e atualmente em sua segunda fase. O objetivo deste artigo se coloca pela importância de se verificar o alinhamento entre as políticas industriais e a produção de conhecimento pelas IES federais de Minas Gerais e, sobretudo, pela Universidade Federal de Minas Gerais (UFMG), que é líder na produção de conhecimento entre as demais instituições federais de ensino superior em Minas Gerais, conforme corroborado por Chiarini et al. (2010). O escopo da análise, portanto, não está em exaurir a temática referente ao papel das IES como atores fundamentais em um Sistema de Inovação, mas sim em contribuir para a agenda de discussão sobre alocação estratégica de recursos em IES como forma de alavancar a pesquisa científica e propiciar o desenvolvimento industrial.

Assim, na seção a seguir, é feita uma revisão da discussão do papel das universidades como atores fundamentais na produção de conhecimento. Argumenta-se que as universidades, nos últimos anos, têm sido encaradas como agentes estratégicos e que a relação universidade-empresa tem se tornado cada vez mais relevante no fortalecimento do processo de desenvolvimento. Posteriormente, abordam-se as áreas estratégicas que são referenciadas pela Política Industrial e de Comércio Exterior. A partir disso, será feita uma apresentação da produção de pesquisa científica nas instituições federais de ensino superior em Minas Gerais para verificar a congruência das mesmas com tais áreas estratégicas. Finda-se esse artigo com algumas considerações e sugestôes de políticas públicas de alocação de recursos nessas instituições.

\section{Da literatura - qualificação dos principais conceitos}

A concepção de paradigma tecnológico foi proposta por Giovanni Dosi, no início dos anos 1980, ao afirmar que esse é um pacote de procedimentos que visam a orientação da investigação e da pesquisa sobre um problema tecnológico, definindo, dessa forma, o contexto, os objetivos a serem alcançados e os recursos a serem utilizados (KUPFER, 1996). Assim, ao consentir a relevância dessa proposição, aceita-se a noção de trajetória tecnoeconômica, entendida como o padrão evolutivo do desenvolvimento de tecnologias feitas pelos agentes econômicos, o qual é função 
de uma série de variáveis que podem afetá-la. Esses conceitos teóricos fazem parte de um arcabouço que entende a economia como um sistema complexo, cujo ambiente encarrega-se de possuir certas propriedades, como a não-ergodicidade, incerteza e incógnitas informacionais (TEBECHRANI, 2009).

Entre os fatores que podem afetar a trajetória tecnoeconômica, tem-se a produção de conhecimento com a sua adequada utilização/aplicação em setores produtivos. Justifica-se, portanto, o esforço identificado na sua produção pelas IES, as quais constituem o principal local para concebê-lo (AROCENA; SUTZ, 2001). Além do processo de criação, as IES são atores responsáveis pela disseminação tanto de novos conhecimentos quanto de novas tecnologias, por meio de pesquisa básica, pesquisa aplicada, desenvolvimento e engenharia, podendo ser encaradas como agentes estratégicos para o catch-up. ${ }^{2}$

Existem dois focos metodológicos, não excludentes entre si, para entender como as universidades podem afetar trajetórias tecnoeconômicas: aquele proposto pelo Sistema de Inovação; e o proposto pela "hélice tríplice". Ambos, no entanto, não formam teorias consolidadas, mas sim métodos heurísticos. Segundo Etzkowitz et al. (2005), o foco da "hélice tríplice" difere daquele apresentado pelo SI à la Nelson (1988), uma vez que este define a empresa como o motor da inovação e as demais organizaçóes dão suporte a estrutura, enquanto o primeiro focaliza a interação entre universidade, indústria e Estado, bem como a criação de organizaçôes híbridas, como incubadoras, para apoiar o processo de start-up.

A geração de novos conhecimentos dentro das universidades tem encontrado respaldo na demonstração de interesse tanto de empresas privadas quanto do Estado. $\mathrm{O}$ debate sobre a interação universidade-estado-empresa é bastante extenso na literatura e, apesar das controvérsias que abriga, não reduz o papel da universidade ao de mero apoio do desenvolvimento tecnológico de setores específicos de atividade econômica, sendo igualmente importante sua função enquanto produtora de conhecimento básico. Da mesma forma, não se pode esperar que a inovação tecnológica seja realizada apenas por empresas com vistas à expansão de suas fatias de mercado. O Estado também tem papel relevante no desenvolvimento de novas tecnologias. Tal simbiose entre esses três agentes foi apontada por Sábato e Botana (1968) e ganhou novo destaque com a "hélice tríplice" (LEYDESDORFF; ETZKIWITZ, 1998; LEYDESDORFF, 2000; ETZKOWITZ et al., 2000; ETZKOWITZ, 2003;

2 De acordo com a abordagem neoschumpeteriana, catch-up é um termo que se refere ao esforço de adesão das inovações tecnológicas ao paradigma vigente, diminuindo a distância até a fronteira tecnológica. 
LEYDESDORFF; MEYER, 2006), a qual reconhece que esses atores podem assumir o papel um dos outros, a fim de que o sistema inovativo funcione adequadamente.

Grosso modo, as universidades assumem a função de prover educação formal, além de produzir conhecimento, o Estado se responsabiliza pelo aparato legal e regulatório, enquanto as empresas produzem e comercializam bens e serviços (VELASCO, 2009).

Já foi amplamente discutido (por teóricos schumpeterianos e evolucionistas) que a empresa é o agente capaz de introduzir a inovação, no entanto, o desenvolvimento tecnológico não é resultado da ação isolada e individualizada da mesma. É nesse contexto que se utilizam as noçōes de Sistemas de Inovação (SI) e "hélice tríplice", ao reconhecer que o desenvolvimento tecnológico é um processo dinâmico e resultado da coletividade, especialmente, da interação entre diferentes agentes econômicos, pois, cada vez mais, os novos paradigmas tecnológicos estão permeados por conhecimentos de natureza científica que se encontram muito próximos da fronteira do saber, daí a importância em fomentar as relações universidade-empresa.

Quando a universidade se aproxima da empresa, verificam-se ganhos de ambos os lados e para a sociedade em geral, devido ao transbordamento do conhecimento proveniente da Pesquisa e Desenvolvimento (P\&D) realizada por meio de novos produtos e processos aprimorados. Contudo, esse transbordamento de conhecimento e a busca pela inovação a partir da relação universidade-empresa podem ser eventualmente retardados, ou mesmo impedidos, devido aos atritos ${ }^{3}$ que afetam essa relação, como sugerem Davenport e Prusak (apud REIS, 2008).

A relação empresa-universidade - como a colaboração para $\mathrm{P} \& \mathrm{D}$, por exemplo - pode ser justificada uma vez que reduz as incertezas intrínsecas ao processo de inovação (TETHER, 2002), diluindo os riscos relacionados às atividades inovativas (HAGEDOORN et al., 2000). A relação pode ser benéfica para as empresas, ao gerar o desenvolvimento de capacidades, aprendizagem e aquisição de conhecimento e tecnologias (MARQUES et al., 2007), contribuindo para que projetos industriais sejam concluídos e/ou auxiliando a implementação de novos projetos (COHEN et al., 2002).

Outros produtos de importância econômica, tanto tangíveis quanto intangíveis, apresentam diversas formas e variam com o tempo e de acordo com a indústria/setor.

3 Segundo Davenport e Prusak (apud REIS, 2008), os principais atritos seriam: falta de confiança mútua; diferenças culturais; falta de tempo e de locais de encontro; falta de capacidade de absorção pelos recipientes; crença de que o conhecimento é prerrogativa de determinados grupos; síndrome do not invented here; intolerância com erros ou necessidade de ajuda; etc. 
Informação científica e tecnológica, equipamentos e instrumentos, habilidades/capital humano, network de capacidades científicas e tecnológicas e protótipos de novos processos e produtos são alguns exemplos da produção gerada a partir da pesquisa universitária e da relação universidade-empresa (MOWERY; SAMPAT, 2005).

No que tange aos benefícios da relação universidade-empresa, tem-se que, do lado das universidades, a parceria com empresas para geração de conhecimento possibilita novas fontes de recursos para pesquisa. As universidades podem se beneficiar de outras formas: a interação com empresas cria temas e problemas de pesquisas, teses, dissertaçôes, trocas de insumos e de informaçôes, etc.

A sociedade, por sua vez, é beneficiada pela parceria universidade-empresa com a geração de novos produtos e processos aprimorados. Além disso, as universidades promovem a formação e o aprimoramento de profissionais, por meio de treinamentos, capacitando-os a trabalhar de acordo com a demanda das empresas, sendo ainda o único local para treinamento de especialistas em número suficiente para sustentar as ciências, medicina, tecnologia e sistemas de comunicação globalizados (NOWOTNY et al., 2001).

Dessa forma, as universidades, por si só, ao formarem pessoas qualificadas, influenciam a capacidade de absorção de conhecimentos pela sociedade, ou seja, elevam a capacidade da sociedade para compreender tecnologias e conhecimentos externos (não produzidos nela) e, consequentemente, para utilizar esses conhecimentos. Isso possibilita que a sociedade seja capaz também de produzir novos conhecimentos e não apenas agir como mera copiadora ou absorvedora do que as universidades criam (ROSENBEG, NELSON, 1994; PAVITT, 1998, NOWOTNY et al., 2001). As universidades acabam tendo impacto no crescimento econômico regional devido à excelência em pesquisa avançada e ao aumento do estoque de capital humano da regiāo (PREMUS, 2003), afinal, os recursos humanos são reconhecidos como um fator determinante do desenvolvimento; é preciso pessoal capacitado em assimilar e saber com um ritmo consistente de mudança tecnológica (PEREZ, 1992). A combinação entre crescimento nos estoques de conhecimento e oferta de capital humano gera retornos crescentes na região do sistema de produção de conhecimento e na comercialização das invenções (PREMUS, 2003).

Portanto, é essencial a função das universidades como geradoras de conhecimento em um Sistema de Inovação (MOWERY; SAMPAT, 2004; MAZZOLENI, 2005; MAZZOLENI; NELSON, 2005). Entretanto, são intrincadas as relações e os papéis de todos os atores envolvidos na produção de conhecimento em um SI, além do papel essencial exercido pela própria sociedade na absorção do mesmo. 
A literatura nacional tem apresentado uma variada gama de estudos que buscam analisar a relação universidade-empresa, como em Gomes (2001), Dagnino e Gomes (2003), Dagnino (2003), Dagnino e Gomes (2003), Baldini e Borgonhoni (2007), Marques et al. (2007), Rapini e Righi (2007), Zawislak e Dalmarco (2009), somente para mencionar alguns. Existem também aqueles cujo enfoque se dá sobre a "hélice tríplice", como Dagnino (2003), Almeida (2004; 2005) e Abdalla et al. (2009). Outros trabalhos visam verificar o papel das IES brasileiras no SI, como Albuquerque (1996; 1998), Cruz (2004), Albuquerque et al. (2005b), Theis et al. (2006), Rapini (2007), Renault et al. (2008), Póvoa e Rapini (2009), Rapini et al. (2009), Esteves e Meirelles (2009), Mello et al. (2009) e Suzigan e Albuquerque (2009). O mesmo tem sido feito em âmbito regional por Silva et al. (2000), Rapini e Campos (2004), Albuquerque et al. (2005a), Rapini et al. (2006), Righi e Rapini (2006), Chiarini et al. (2010), Chiarini et al. ( no prelo) ao terem como foco de análise o Estado de Minas Gerais.

\section{A produção científica das IES de Minas Gerais e áreas da PITCE}

\subsection{A opção por Minas Gerais}

As universidades federais brasileiras não formam um grupo homogêneo de criação de conhecimento, havendo algumas mais intensivas na geração e produção de conhecimento e invenções do que outras. Considerando-se que não é a intenção deste trabalho discutir a relevância ou a qualidade da formação oferecida pelas IES privadas brasileiras, cabe aqui apenas destacar que são raras as instituiçôes privadas de ensino superior que se dedicam à pesquisa científica, ficando a produção de conhecimento científico a cargo, principalmente, das universidades públicas.

Consultando a Sinopse Estatística da Educação Superior de 2008, do Instituto Nacional de Estudos e Pesquisas Educacionais Anísio Teixeira (Inep), observa-se que a maioria dos doutores docentes nas IES brasileiras está em universidades públicas (federais, estaduais e municipais). (Gráfico 1). A maior representatividade de docentes doutores nas universidades federais, quando comparadas às particulares, corrobora a maior capacidade de produção de conhecimento pelas universidades públicas, uma vez que a presença de profissionais qualificados, interagindo e produzindo em um mesmo ambiente acadêmico, propicia a produção de conhecimento. 


\section{GRÁFICO 1}

Distribuição de docentes doutores nas instituições de ensino superior, segundo rede de ensino Brasil - 2008

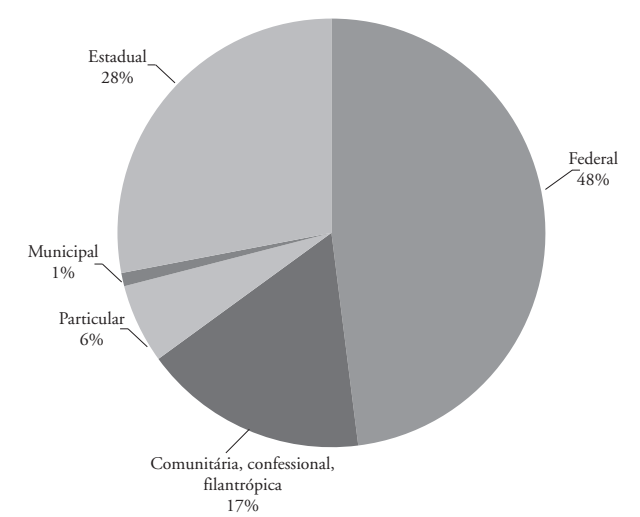

Fonte: Instituto Nacional de Estudos e Pesquisas Educacionais Anísio Teixeira - Inep. Sinopse Estatística da Educação Superior. 2008. Elaboração dos autores

Segundo o Inep, em 2008, havia 55 universidades federais, no Brasil: 19 na Região Sudeste; 14 no Nordeste; nove no Sul; oito no Norte; e cinco no Centro-Oeste. Conforme Chiarini et al. (2010), ao se atentar para a distribuição de universidades federais no território brasileiro, nota-se que Minas Gerais é um Estado atípico, pois, quando comparado aos demais, abriga o maior número de universidades públicas federais, respondendo por 20\% do total nacional (Quadro 1).

$\mathrm{Na}$ esfera produtiva, Minas Gerais também se apresenta como um dos Estados mais industrializados do país, sendo o terceiro maior parque industrial, atrás apenas de São Paulo e Rio de Janeiro. Pela Pesquisa Industrial de Inovação Tecnológica - Pintec de 2008, do IBGE, as empresas industriais localizadas em Minas Gerais representaram $13,6 \%$ do total de empresas industriais brasileiras que implementaram inovações de produto e/ou serviço, no período 2006-2008, perdendo apenas para São Paulo, com $32,3 \%$ do total. ${ }^{4}$

Outra característica que chama a atenção para Minas Gerais é a alta participação do financiamento público para atividades de pesquisa e desenvolvimento das empresas do Estado, respondendo por $38 \%$ do total de financiamento para estas atividades, enquanto, no Brasil, esse valor corresponde a 10\%, o que realça o importante papel do setor público no SI mineiro (PINTEC, 2010).

4 De acordo com a Pintec 2008, 41.262 empresas brasileiras implementaram inovações de produtos e/ou processos, no período de 2006-2008. Destas, 38.299 pertencentes à indústria extrativa ou de transformação, entre as quais, destacam-se aquelas presentes nos estados de São Paulo (12.379), Minas Gerais (5.208) e Rio Grande do Sul (4.029). 
Atividades de pesquisa científica e tecnológica das IES federais de MG e as diretrizes da PITCE

\section{QUADRO 1}

Instituições federais de ensino superior localizadas em Minas Gerais

\begin{tabular}{ll}
\hline CEFET/MG & Centro Federal de Educação Tecnológica de Minas Gerais (Belo Horizonte) \\
IFMG & $\begin{array}{l}\text { Instituto Federal de Educação, Ciência e Tecnologia de Minas Gerais (Bambuí) } \\
\text { IFN/MG }\end{array}$ \\
$\begin{array}{ll}\text { Instituto Federal de Educação, Ciência e Tecnologia do Norte de Minas Gerais (Montes } \\
\text { Claros) }\end{array}$ \\
IFS/MG & Instituto Federal de Educação, Ciência e Tecnologia do Sul de Minas Gerais (Pouso Alegre) \\
IFSE/MG & $\begin{array}{l}\text { Instituto Federal de Educação, Ciência e Tecnologia do Sudeste de Minas Gerais (Juiz } \\
\text { de Fora) }\end{array}$ \\
IFT/MG & Instituto Federal de Educação, Ciência e Tecnologia do Triângulo Mineiro (Uberaba) \\
UFJF & Universidade Federal de Juiz de Fora \\
UFLA & Universidade Federal de Lavras \\
UFMG & Universidade Federal de Minas Gerais \\
UFOP & Universidade Federal de Ouro Preto \\
UFSJ & Universidade Federal de São João Del Rei \\
UFTM & Universidade Federal do Triângulo Mineiro \\
UFU & Universidade Federal de Uberlândia \\
UFV & Universidade Federal de Viçosa \\
UFVJM & Universidade Federal dos Vales do Jequitinhonha e Mucuri \\
UNIFAL & Universidade Federal de Alfenas \\
UNIFEI & Universidade Federal de Itajubá \\
\hline
\end{tabular}

Fonte: MEC. Elaboração dos autores.

Assim, considerando-se as três esferas - universidade, Estado e empresa -, observa-se que Minas Gerais conta com considerável capacidade de geração de conhecimento via IES, apresenta alto grau de participação do setor público no incentivo às inovaçôes empresariais e desempenha papel de destaque no setor produtivo nacional.

Pelo exposto, Minas Gerais possui papel estratégico na política de ciência e tecnologia brasileira, tendo nas IES federais seu agente principal de geração e disseminação de conhecimento. Dessa forma, torna-se interessante verificar a ocorrência de possível complementaridade entre as pesquisas desenvolvidas pelas IES federais em Minas Gerais e as "opçōes estratégicas" e "atividades portadoras de futuro" definidas pela Política Industrial Tecnológica e de comércio Exterior - PITCE. 
A seguir são apresentados os aspectos gerais da PITCE, bem como a metodologia e as fontes de dados utilizadas para o desenvolvimento da análise.

\subsection{A Política Industrial Tecnológica e de Comércio Exterior - PITCE}

O reconhecimento de que a indústria é componente essencial do desenvolvimento sustentado da economia, por parte do governo brasileiro, não é novo. Embora não seja objetivo dessa seção apresentar um panorama histórico das políticas públicas efetuadas pelo governo federal para promover a indústria, vale mencionar que, em um período historiográfico recente, o governo tem incentivado a indústria nacional de diversas formas e pode-se dizer que uma política intencional efetiva com investimentos públicos significativos nos setores industriais iniciou-se no período desenvolvimentista de JK (VILELLA, 2005). Desde então, vivenciou-se uma fase de políticas industriais (anos 1960 e 1970), cujo "foco estava na construção de capacidade física (fábricas) sem preocupação com o padrão competitivo internacional, e os anos 90 ouviram o discurso da competitividade internacional apartado de política industrial"'s (SALERNO, 2004, p. 14).

Já no início da década de 2000, o governo passou a entender a inovação como elemento-chave para o crescimento da competitividade tanto industrial quanto nacional. Dessa forma, a dinâmica da inovação e a difusão de tecnologias foram entendidas como facilitadores da disputa e da conquista de novos mercados e, para tanto, políticas públicas foram equacionadas, tendo como objetivo o aumento da eficiência econômica e do desenvolvimento e da difusão de tecnologias, como foi o caso da Política Industrial, Tecnológica e de Comércio Exterior (PITCE), lançada em 2004, no governo Lula da Silva, a qual valoriza a inovação como meio de desenvolvimento, influenciado pela escola evolucionária (CAMPANÁRIO et al., 2005).

Ela [a PITCE] estará focada no aumento da eficiência da estrutura produtiva, aumento da capacidade de inovação das empresas brasileiras e expansão das exportaçôes. Esta é a base para uma maior inserção do país no comércio internacional, estimulando os setores onde o Brasil tem maior capacidade ou necessidade de desenvolver vantagens competitivas, abrindo caminhos para inserção nos setores mais dinâmicos dos fluxos de troca internacionais. (PITCE, 2003, p. 2-3)

5 De acordo com Salerno (2004), os anos 1990 significaram um período de ampla abertura econômica (iniciada no governo Collor), reduzindo a proteção à indústria doméstica brasileira. Além disso, a desvantagem competitiva da estrutura produtiva brasileira foi mantida por longo tempo nessa década, devido à introdução da paridade cambial do Plano Real. 
A PITCE reconhece que certas áreas, intensivas em conhecimento, são "portadoras de futuro" e estratégicas, devendo, por isso, ser estimuladas, a partir da concentração de esforços conjuntos. Assim, tal política visa orientar a ação pública na busca de vantagens comparativas dinâmicas e aumento de produtividade (CAMPANÁRIO et al., 2005). As áreas estratégicas são definidas pela PITCE (2003, p. 16) considerando-se que:

a) apresentam dinamismo crescente e sustentável; b) são responsáveis por parcelas expressivas dos investimentos internacionais em Pesquisa e Desenvolvimento; c) abrem novas oportunidades de negócios; d) relacionam-se diretamente com a inovação de processos, produtos e formas de uso; e) promovem o adensamento do tecido produtivo, ef) são importantes para o futuro do pais e apresentam potencial para o desenvolvimento de vantagens comparativas dinâmicas.

Enquadram-se nesses requisitos apresentados pela PITCE as seguintes áreas: software; fármacos; biotecnologia; biomassa; nanotecnologia; semicondutores; e bens de capital. Tais áreas podem ser articuladas em dois eixos de atuação, ${ }^{6}$ conforme a PITCE: opçōes estratégicas (semicondutores, software, bens de capital e fármacos); e atividades portadoras de futuro (biotecnologia, nanotecnologia e biomassa), as quais têm o potencial de mudar radicalmente processos/produtos (SALERNO, 2004). Para fins desse estudo, tanto as opções estratégicas quanto as atividades portadoras de futuro serão tratadas como "áreas estratégicas" em sentido amplo, caracterizadas da forma apresentada acima, de acordo com a PITCE (2003).

\subsection{Metodologia e fontes de dados}

Vistos os aspectos gerais da PITCE e apresentada a motivação pela escolha de Minas Gerais como foco da análise, foram delimitadas as áreas do conhecimento observadas na avaliação desejada, com base na classificação adotada pela Coordenação de Aperfeiçoamento de Pessoal de Nível Superior (Capes). ${ }^{7}$ As grandes áreas do conhecimento se dividem em: Ciências Exatas e da Terra; Ciências Biológicas;

6 Existe um terceiro eixo de atuação da PITCE que não está no escopo de análise desse estudo: linhas de ação horizontais, que englobam inovação e desenvolvimento tecnológico, inserção externa, modernização industrial e melhoria do ambiente institucional/ampliação da capacidade e escala produtiva.

7 Disponível em: <http://www.capes.gov.br/images/stories/download/avaliacao/TabelaAreasConheci mento_042009. pdf >. Acesso em: 02 de março de 2011. 
Engenharias; Ciências da Saúde; Ciências Agrárias; Ciências Sociais Aplicadas; Ciências Humanas; Linguística, Letras e Artes; e Multidisciplinar.

A fim de tornar a análise mais clara, optou-se pela realização de um cruzamento das áreas estratégicas em sentido amplo da PITCE com as grandes áreas de conhecimento mencionadas anteriormente. Para fazer a adequada alocação das áreas da PITCE dentro das áreas de conhecimento, foi observada a classificação adotada pela Capes. O produto de tal cruzamento pode ser visto no Quadro 2.

\section{QUADRO 2}

Áreas estratégicas em sentido amplo da PITCE, segundo grandes áreas de conhecimento

\begin{tabular}{l|l}
\multicolumn{1}{c|}{$\begin{array}{c}\text { Grandes áreas do conhecimento } \\
\text { (Capes) }\end{array}$} & \multicolumn{1}{c}{ PITCE } \\
\hline Ciências Exatas e da Terra & Software \\
Engenharias & Semicondutores \\
Ciências da Saúde & Bens de capital \\
Ciências Agrárias & Fármacos \\
Ciências Biológicas & Biomassa \\
Ciências Sociais Aplicadas & - \\
Ciências Humanas & - \\
Linguítica, Letras e Artes & - \\
Multidisciplinar & - \\
\hline
\end{tabular}

Fonte: PITCE e Capes. Elaboração dos autores.

Nota: Embora haja um cruzamento direto entre áreas do conhecimento (Capes) e áreas estratégicas (PITCE), nada impede que pesquisas sobre determinada área estratégica sejam realizadas por pesquisadores de outras áreas do conhecimento. Por exemplo, apesar de a área estratégica software pertencer às Ciências Exatas e da Terra, pesquisas sobre softwares são realizadas por demais áreas, como Agrárias, Engenharias, Ciências da Saúde, Ciências Sociais Aplicadas, Ciências Humanas e até mesmo Linguística, Letras e Artes.

Para verificar o perfil das publicações e pesquisas realizadas pelas IES federais de Minas Gerais, são utilizadas informaçōes do Diretório de Grupos de Pesquisa do Conselho Nacional de Desenvolvimento Científico e Tecnológico (CNPq), bem do Ministério da Educação (MEC), além de outras fontes como publicações científicas.

O Diretório do CNPq traz informações sobre os recursos humanos constituintes de cada grupo de pesquisa (pesquisadores, estudantes e técnicos), suas linhas de pesquisa e os setores envolvidos, entre outras características. Assim, é possível 
verificar quais as principais linhas de pesquisa das IES federais de Minas Gerais e sua relevância quando se consideram os setores prioritários da PITCE.

A partir dessas áreas estratégicas em sentido amplo, procura-se caracterizar as pesquisas científicas de base desenvolvidas pelas instituiçōes federais de ensino superior localizadas em Minas Gerais, a fim de verificar sua coerência com tais áreas, sobretudo quanto à sua relevância para o desenvolvimento industrial e científicotecnológico do Brasil.

A princípio, a análise busca apresentar características das instituições federais de ensino superior de Minas Gerais, destacando a alocação de recursos e o desenvolvimento de pesquisas científicas, em geral. Posteriormente, aborda-se a alocação de recurso em cada IES federal de Minas Gerais no que tange às áreas estratégicas em sentido amplo definidas pela PITCE.

\section{Apresentação e discussão dos resultados}

\subsection{Instituições federais de ensino superior: oferta de conhecimento}

Apesar da considerável parcela de IES federais presentes no território mineiro, a produção científica e a alocaçãa de recursos humanos apresentam-se bastante concentradas em algumas dessas instituições. A distribuição de pesquisadores entre as IES federais de Minas Gerais, segundo dados do Censo do Diretório dos Grupos de Pesquisa do CNPq (2008), mostra que, dos 8.537 pesquisadores alocados nas IES federais de MG, em 2008, 40\% encontravam-se na UFMG, $14 \%$ na UFV e $11 \%$ na UFU.

Tal concentração de pesquisadores em três universidades afeta também a distribuição dos grupos de pesquisa. Em 2008, dos 1.612 grupos de pesquisa das IES federais de MG cadastrados junto ao Diretório do CNPq, 630 estavam na UFMG, o que corresponde a cerca de $40 \%$ do total, enquanto a UFV contava aproximadamente $15 \%$ e a UFU com cerca de $12 \%$ dos grupos (Tabela 1 ).

Segundo Chiarini et al. (2010), a UFMG é líder na produção de conhecimento entre as universidades mineiras, consistindo-se, nesse aspecto, no ator principal do Sistema Mineiro de Inovação. Além disso, também são destacadas as universidades federais "especializadas", como é o caso da Unifei e da UFV, que são altamente focadas em engenharia e ciências agrárias, respectivamente. 
TABELA 1

Distribuição dos pesquisadores e dos grupos de pesquisa registrados no CNPq, segundo as instituições de ensino federais

Estado de Minas Gerais - 2008

Em porcentagem

\begin{tabular}{l|c|c}
\hline \multicolumn{1}{c|}{ IES federais } & Pesquisadores & Grupos de Pesquisa \\
\hline UFMG & 40,03 & 39,08 \\
UFV & 14,27 & 14,39 \\
UFU & 11,43 & 11,79 \\
UFJF & 9,35 & 9,93 \\
UFLA & 5,80 & 4,28 \\
UFOP & 3,88 & 4,16 \\
UFSJ & 3,06 & 3,35 \\
CEFET/MG & 2,68 & 2,36 \\
UNIFEI & 2,51 & 2,67 \\
UFVJM & 2,34 & 3,29 \\
UFTM & 1,97 & 2,11 \\
UNIFAL & 1,71 & 1,55 \\
IFMG & 0,40 & 0,31 \\
IFT/MG & 0,36 & 0,50 \\
IFN/MG & 0,21 & 0,23 \\
Total & $\mathbf{1 0 0 , 0 0}$ & $\mathbf{1 0 0 , 0 0}$ \\
\hline
\end{tabular}

Fonte: Plano Tabular do Diretório de Grupos de Pesquisa do CNPq, Censo 2008. Elaboração dos autores. Nota: Os IFS/MG e IFSE/MG não apresentaram nenhum grupo cadastrado.

Em 2008, Minas Gerais reuniu 9,36\% dos grupos de pesquisa de todo o país e 9,90\% do total de pesquisadores. ${ }^{8}$ A desagregação desses dados por grandes áreas do conhecimento pode ser verificada na Tabela 2. Nota-se que Minas Gerais está sempre entre os quatro Estados que mais possuem grupos de pesquisa.

De acordo com os dados do Plano Tabular do Diretório de Grupos de Pesquisa do CNPq, Minas Gerais 9 respondeu, em 2008, por 10,36\% dos artigos publicados, ficando atrás somente do Rio Grande do Sul (10,65\%), Rio de Janeiro $(11,72 \%)$ e São Paulo (32,11\%). Analisando-se esses dados, segundo as

8 Aqui foi considerada toda e qualquer instituição cadastrada no CNPq que realiza pesquisa, a saber: universidades federais, estaduais, municipais e privadas; instituições de educação superior não universitárias (centros universitários, faculdades integradas, faculdades isoladas, institutos, escolas, centros de educação tecnológica, etc.), que possuam pelo menos um curso de pós-graduação (mestrado ou doutorado) reconhecido pela Capes/MEC; institutos públicos de pesquisa científica; institutos tecnológicos públicos e centros federais de educação tecnológica e laboratórios de pesquisa e desenvolvimento de empresas estatais. Considerando-se o total de IES de Minas Gerais, verifica-se que, em 2008, 75\% dos grupos de pesquisa e $80 \%$ dos pesquisadores encontram-se nas IES federais (Dados do Plano Tabular do Diretório de Grupos de Pesquisa do CNPq).

9 Ver nota 9. 
grandes áreas do conhecimento, verifica-se que Minas Gerais está entre os quatro maiores produtores de conhecimento científico e tecnológico do país (Tabela 3), com destaque para as produções nas ciências agrárias, ficando atrás somente do Estado de São Paulo.

TABELA 2

Distribuição dos grupos de pesquisa, por grandes áreas do conhecimento Estados selecionados - 2008

\begin{tabular}{|c|c|c|c|c|c|c|c|c|c|}
\hline Estados & $\begin{array}{l}\text { Ciências } \\
\text { Agrárias }\end{array}$ & $\begin{array}{l}\text { Ciências } \\
\text { Biológi- } \\
\text { cas }\end{array}$ & $\begin{array}{l}\text { Ciências } \\
\text { da Saúde }\end{array}$ & $\begin{array}{c}\text { Ciências } \\
\text { Exatas }\end{array}$ & $\begin{array}{c}\text { Ciências } \\
\text { H u m a - } \\
\text { nas }\end{array}$ & $\begin{array}{l}\text { Ciências } \\
\text { Sociais }\end{array}$ & $\begin{array}{c}\text { E n g e - } \\
\text { nharias }\end{array}$ & $\begin{array}{l}\text { Linguís- } \\
\text { tica, Le- } \\
\text { tras e } \\
\text { Artes }\end{array}$ & $\begin{array}{c}\text { Tod a s } \\
\text { Área } \mathrm{s} \\
\begin{array}{c}\text { Agrega- } \\
\text { das }\end{array}\end{array}$ \\
\hline MG & 14,10 & 8,68 & 8,10 & 9,22 & 8,46 & 8,75 & 9,25 & 11,33 & 9,36 \\
\hline RJ & 5,97 & 16,32 & 10,60 & 13,60 & 13,60 & 10,97 & 15,53 & 13,19 & 12,19 \\
\hline RS & 10,29 & 9,27 & 10,40 & 8,55 & 8,55 & 10,45 & 9,38 & 9,88 & 10,10 \\
\hline SP & 20,44 & 27,6 & 35,90 & 27,55 & 27,55 & 21,76 & 24,61 & 22,79 & 26,04 \\
\hline $\begin{array}{l}\text { Demais } \\
\text { Estados }\end{array}$ & 49,2 & 38,13 & 35 & 41,08 & 41,84 & 48,07 & 41,23 & 42,81 & 42,31 \\
\hline Total & 100,00 & 100,00 & 100,00 & 100,00 & 100,00 & 100,00 & 100,00 & 100,00 & 100,00 \\
\hline
\end{tabular}

Fonte:Plano Tabular do Diretório de Grupos de Pesquisa do CNPq, Censo 2008. Elaboração dos autores. Nota: Foram considerados os grupos de pesquisa de toda e qualquer instituição cadastrada no CNPq que realiza pesquisa.

TABELA 3

Distribuição da produção bibliográfica, por grandes áreas do conhecimento Estados selecionados - 2008

\begin{tabular}{|c|c|c|c|c|c|c|c|c|c|}
\hline Estados & $\begin{array}{l}\text { Ciências } \\
\text { Agrárias }\end{array}$ & $\begin{array}{l}\text { Ciências } \\
\text { Biológi- } \\
\text { cas }\end{array}$ & $\begin{array}{l}\text { Ciências } \\
\text { da Saúde }\end{array}$ & $\begin{array}{c}\text { Ciências } \\
\text { Exatas }\end{array}$ & $\begin{array}{c}\text { Ciências } \\
\text { H u m a - } \\
\text { nas }\end{array}$ & $\begin{array}{l}\text { Ciências } \\
\text { Sociais }\end{array}$ & $\begin{array}{c}\text { E n g e - } \\
\text { nharias }\end{array}$ & $\begin{array}{l}\text { Linguís- } \\
\text { tica, Le- } \\
\text { tras e } \\
\text { Artes }\end{array}$ & $\begin{array}{c}\text { Tod a s } \\
\text { Ár e a s } \\
\text { Agrega- } \\
\text { das }\end{array}$ \\
\hline MG & 17,70 & 10,01 & 8,31 & 8,79 & 7,87 & 9,95 & 10,26 & 13,03 & 10,36 \\
\hline RJ & 6,01 & 14,44 & 11,43 & 14,22 & 12,47 & 10,45 & 15,73 & 13,92 & 11,72 \\
\hline RS & 10,32 & 10,66 & 10,53 & 8,78 & 14,28 & 13,74 & 10,00 & 10,85 & 10,65 \\
\hline SP & 24,36 & 29,51 & 42,07 & 33,65 & 26,82 & 25,66 & 33,09 & 26,57 & 32,11 \\
\hline $\begin{array}{l}\text { Demais } \\
\text { Estados }\end{array}$ & 41,61 & 35,38 & 27,66 & 34,56 & 38,56 & 40,20 & 30,92 & 35,63 & 35,16 \\
\hline Total & 100,00 & 100,00 & 100,00 & 100,00 & 100,00 & 100,00 & 100,00 & 100,00 & 100,00 \\
\hline
\end{tabular}

Fonte: Plano Tabular do Diretório de Grupos de Pesquisa do CNPq, Censo 2008. Elaboração dos autores. Nota: Produção bibliográfica refere-se ao somatório dos artigos científicos (nacionais e internacionais) publicados em revistas indexadas, por pesquisadores e estudantes. Não há dupla contagem nos quantitativos da produção. 


\subsection{IES federais de Minas Gerais e a produção de conhecimento em áreas estratégicas}

A maior concentração de grupos de pesquisa das IES federais de Minas Gerais ${ }^{10}$ encontra-se nas Ciências Agrárias, ${ }^{11}$ com 29,9\% desses grupos, seguidas pelas Ciências da Saúde ${ }^{12}$ (17,5\%). Contudo, em cada IES federal de Minas, existem grandes áreas de conhecimento que são mais ou menos concentradas, como são os casos da Unifei e Cefet/MG, que possuem, respectivamente, mais de 58,7\% e 42,5\% dos grupos de pesquisa na área das Engenharias, ${ }^{13}$ e da UFLA e UFV, com a maioria dos grupos voltados para área de Agrárias (74,9\% e 66\%, respectivamente). Outras instituições, como a UFMG, por exemplo, são bastante plurais, não havendo um predomínio marcante de pesquisa em uma ou outra grande área do conhecimento (Tabela 4).

Existe uma aglomeração espacial dos grupos de pesquisa. Concentram-se na UFMG basicamente todas as grandes áreas de pesquisa, com exceção das Ciências Agrárias, cuja maior predominância ocorre na UFV e na Ufla. Certamente, essa centralização na UFMG deve-se ao fato, por exemplo, de esta instituição possuir a maior proporção de pesquisadores. Em 2008, dos mais de 11 mil pesquisadores em todas IES espalhadas por Minas Gerais, 29\% estavam alocados na UFMG, segundo dados do Plano Tabular do Diretório de Grupos de Pesquisa do CNPq.

No que tange às áreas estratégicas em sentido amplo - software, fármacos, biotecnologia, biomassa, nanotecnologia e semicondutores ${ }^{14}$-, verifica-se que $26 \%$ dos grupos de pesquisas das IES federais de Minas concentram-se esforços em biotecnologia, seguida por fármacos (23\%) e software (16\%) (Gráfico 2).

10 De acordo com os dados do Censo do Diretório de Grupos de Pesquisa do CNPq (2008), em Minas Gerais, existem 2.135 grupos de pesquisas cadastrados espalhados por todas IES mineiras, dos quais 1.612 estão em IES federais.

11 A grande área do conhecimento denominada Ciências Agrárias, de acordo com a Coordenação de Aperfeiçoamento de Pessoal de Nível Superior (Capes), compreende as seguintes áreas de estudo: agronomia; recursos florestais e engenharia florestal; engenharia agrícola; zootecnia; recursos pesqueiros e engenharia de pesca; medicina veterinária; e ciência e tecnologia de alimentos.

12 A grande área do conhecimento denominada Ciências da Saúde, de acordo com a Coordenação de Aperfeiçoamento de Pessoal de Nível Superior (Capes), compreende as seguintes áreas de estudo: medicina; nutrição; odontologia; farmácia; enfermagem; saúde coletiva; educação física; fonoaudiologia; fisioterapia e terapia ocupacional.

13 A grande área do conhecimento denominada Engenharias, de acordo com a Coordenação de Aperfeiçoamento de Pessoal de Nível Superior (Capes), compreende as seguintes áreas de estudo: engenharia civil; engenharia sanitária; engenharia de transportes; engenharia de minas; engenharia de materiais e metalúrgica; engenharia química; engenharia nuclear; engenharia mecânica; engenharia de produção; engenharia naval e oceânica; engenharia aeroespacial; engenharia elétrica; e engenharia biomédica.

14 Optou-se por desconsiderar, na análise, o setor de bens de capital. 
TABELA 4

Distribuiç̧ão dos grupos de pesquisa registrados no Diretório de Pesquisa do CNPq, nas instituições de ensino superior federais, por grandes áreas de conhecimento Estado de Minas Gerais - 2008

\begin{tabular}{|c|c|c|c|c|c|c|c|c|c|}
\hline $\begin{array}{c}\text { IES } \\
\text { federais }\end{array}$ & $\begin{array}{l}\text { Ciências } \\
\text { Agrárias }\end{array}$ & $\begin{array}{c}\text { Ciências } \\
\text { Exatas e } \\
\text { da Terra }\end{array}$ & $\begin{array}{l}\text { Engenha- } \\
\text { rias }\end{array}$ & $\begin{array}{l}\text { Ciências } \\
\text { da Saúde }\end{array}$ & $\begin{array}{l}\text { Ciências } \\
\text { B i o I ó - } \\
\text { gicas }\end{array}$ & $\begin{array}{l}\text { Ciências } \\
\text { Socia is } \\
\text { Aplicadas }\end{array}$ & $\begin{array}{l}\text { Ciências } \\
\text { Humanas }\end{array}$ & $\begin{array}{l}\text { Linguísti- } \\
\text { ca, Letras } \\
\text { e Artes }\end{array}$ & Total \\
\hline Cefet/MG & 4,4 & 10,4 & 42,5 & - & - & - & 35,3 & 7,4 & 100,0 \\
\hline IFMG & 88,9 & - & 11,1 & - & - & - & - & - & 100,0 \\
\hline IFN/MG & 80,0 & - & - & - & - & - & 20,0 & - & 100,0 \\
\hline IFT/MG & 95,8 & - & - & 2,1 & - & 2,1 & 0,0 & - & 100,0 \\
\hline UFJF & - & 20,3 & 8,2 & 21,4 & 17,4 & 10,0 & 19,0 & 3,7 & 100,0 \\
\hline Ufla & 74,9 & 7,5 & 1,2 & 3,3 & 8,9 & 4,2 & - & - & 100,0 \\
\hline UFMG & 10,2 & 14,1 & 11,0 & 27,3 & 19,0 & 5,7 & 7,0 & 5,7 & 100,0 \\
\hline Ufop & - & 16,2 & 20,7 & 18,3 & 28,6 & 3,7 & 9,2 & 3,3 & 100,0 \\
\hline UFSJ & - & 19,1 & 20,3 & 4,3 & 15,2 & 4,6 & 30,9 & 5,6 & 100,0 \\
\hline UFTM & - & 3,3 & - & 72,1 & 19,4 & - & 1,6 & 3,6 & 100,0 \\
\hline UFU & 15,2 & 11,5 & 10,5 & 14,3 & 26,2 & 4,3 & 14,8 & 3,1 & 100,0 \\
\hline UFV & 66,0 & 8,8 & 4,2 & 3,8 & 9,7 & 5,0 & 1,6 & 0,8 & 100,0 \\
\hline UFVJM & 54,6 & 15,7 & - & 21,4 & 8,2 & 0,1 & - & - & 100,0 \\
\hline Unifal & 2,8 & 36,8 & 1,5 & 33,8 & 22,5 & - & 2,5 & - & 100,0 \\
\hline Unifei & 3,2 & 26,5 & 58,7 & - & - & 5,4 & 6,1 & - & 100,0 \\
\hline Total & 29,9 & 12,6 & 8,8 & 17,5 & 16,1 & 5,1 & 6,8 & 3,3 & 100,0 \\
\hline
\end{tabular}

Fonte: Plano Tabular do Diretório de Grupos de Pesquisa do CNPq, Censo 2008. Elaboração dos autores.

Nota: Os IFS/MG e IFSE/MG não apresentaram nenhum grupo cadastrado.

TABELA 5

Distribuição dos grupos de pesquisa registrados no Diretório de Pesquisa do CNPq, por grandes áreas, segundo instituições de ensino superior federais Estado de Minas Gerais - 2008

\begin{tabular}{|c|c|c|c|c|c|c|c|c|}
\hline $\begin{array}{c}\text { IES } \\
\text { federais }\end{array}$ & $\begin{array}{c}\text { Ciências } \\
\text { Agrárias }\end{array}$ & $\begin{array}{c}\text { Ciências } \\
\text { Exatas e } \\
\text { da Terra }\end{array}$ & $\begin{array}{l}\text { Engenha- } \\
\text { rias }\end{array}$ & $\begin{array}{l}\text { Ciências da } \\
\text { Saúde }\end{array}$ & $\begin{array}{l}\text { Ciên cias } \\
\text { Biológicas }\end{array}$ & $\begin{array}{l}\text { Ciências } \\
\text { Sociais } \\
\text { Aplicadas }\end{array}$ & $\begin{array}{l}\text { Ciências } \\
\text { Humanas }\end{array}$ & $\begin{array}{l}\text { Ling uís - } \\
\text { tica, Letras } \\
\text { e Artes }\end{array}$ \\
\hline Cefet/MG & 0,1 & 0,6 & 3,3 & - & - & - & 3,5 & 1,5 \\
\hline IFMG & 0,2 & - & 0,1 & - & - & - & - & - \\
\hline IFN/MG & 0,2 & - & - & - & - & - & 0,3 & - \\
\hline IFT/MG & 0,8 & - & - & - & - & 0,1 & 0,0 & - \\
\hline UFJF & - & 9,7 & 5,6 & 7,3 & 6,5 & 11,8 & 16,8 & 6,7 \\
\hline Ufla & 23,3 & 5,5 & 1,2 & 1,7 & 5,1 & 7,7 & - & - \\
\hline UFMG & 13,5 & 44,5 & 49,6 & 61,9 & 47,0 & 44,1 & 40,8 & 69,2 \\
\hline Ufop & - & 3,7 & 6,8 & 3,0 & 5,1 & 2,1 & 3,9 & 2,9 \\
\hline UFSJ & - & 2,1 & 3,2 & 0,3 & 1,3 & 1,2 & 6,2 & 2,3 \\
\hline UFTM & - & 0,5 & - & 8,1 & 2,4 & - & 0,5 & 2,2 \\
\hline UFU & 4,9 & 8,8 & 11,5 & 7,8 & 15,6 & 8,0 & 20,9 & 9,2 \\
\hline UFV & 53,1 & 16,9 & 11,6 & 5,2 & 14,5 & 23,7 & 5,8 & 5,9 \\
\hline UFVJM & 3,6 & 2,4 & - & 2,4 & 1,0 & 0,1 & - & - \\
\hline Unifal & 0,1 & 3,1 & 0,2 & 2,1 & 1,5 & - & 0,4 & - \\
\hline Unifei & 0,1 & 2,2 & 7,0 & - & - & 1,1 & 0,9 & - \\
\hline Total & 100,0 & 100,0 & 100,0 & 100,0 & 100,0 & 100,0 & 100,0 & 100,0 \\
\hline
\end{tabular}

Fonte: Plano Tabular do Diretório de Grupos de Pesquisa do CNPq, Censo 2008. Elaboração dos autores.

Nota: Produção bibliográfica refere-se ao somatório dos artigos científicos (nacionais e internacionais) publicados em revistas indexadas, por pesquisadores e estudantes. Não há dupla contagem nos quantitativos da produção. 


\section{GRÁFICO 2}

Distribuição dos grupos de pesquisa das instituições de ensino superior federais, por área estratégica

Estado de Minas Gerais - 2008

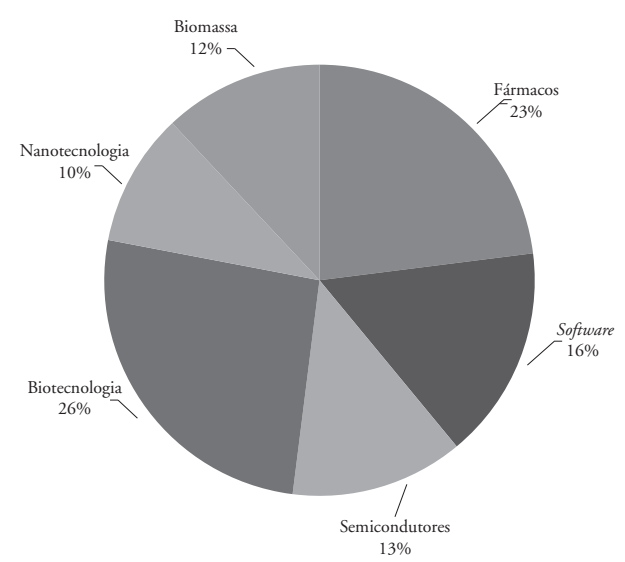

Fonte: Plano Tabular do Diretório de Grupos de Pesquisa do CNPq, Censo 2008. Elaboração dos autores.

Do total de pesquisadores registrados nos Grupos de Pesquisa do CNPq (8.537), 23\% encontram-se alocados em pesquisas em áreas estratégicas (ou seja, 1.932 pesquisadores espalhados por Minas Gerais). Contudo, a distribuição por área estratégica não é homogênea, dessa forma, a área que apresenta mais pesquisadores é a de biotecnologia com 33\% desses, seguida da área de fármacos (23\%), desenvolvimento de software (14\%), biomassa (11\%), semicondutores $(10 \%)$ e nanotecnologia (8\%) (Gráfico 3).

Analisando cada IES federal de Minas Gerais que apresenta pesquisa em áreas estratégicas, observa-se que, na Unifal, $55 \%$ do total de pesquisadores estão alocados nestas áreas, enquanto na UFMG essa proporção corresponde a 19\% (Gráfico 4). 
GRÁFICO 3

Distribuição dos pesquisadores em áreas estratégicas das IES federais, por área Estado de Minas Gerais - 2008

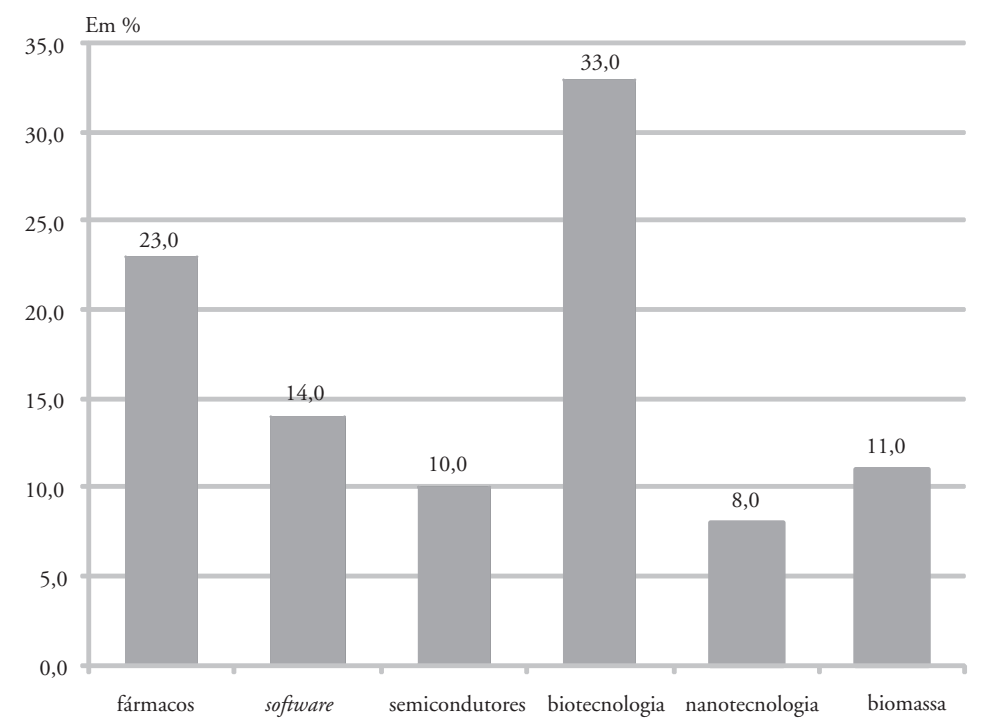

Fonte: Plano tabular do Diretório de Grupos de Pesquisa do CNPq, Censo 2008. Elaboração dos autore

GRÁFICO 4

Distribuição dos pesquisadores em áreas estratégicas, por instituição de ensino superior federal Estado de Minas Gerais - 2008

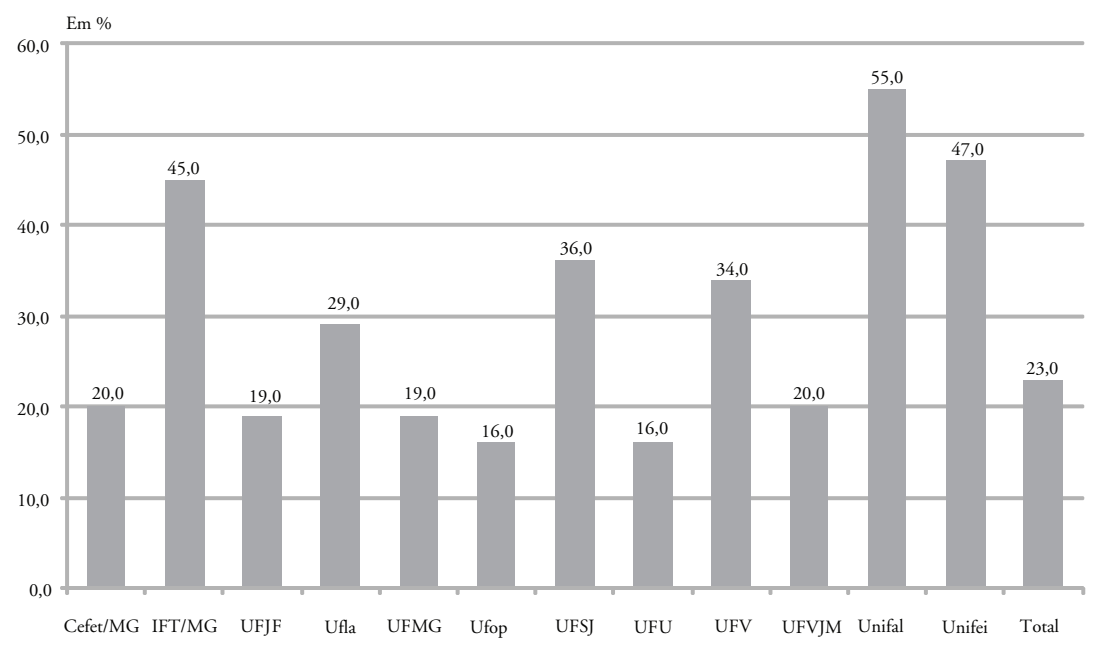

Fonte: Plano tabular do Diretório de Grupos de Pesquisa do CNPq, Censo 2008. Elaboração dos autores. Nota: As demais IES federais não apresentaram nenhum grupo em área estratégica cadastrados. 
Quando se observa o volume de pesquisadores alocados, a UFMG é a principal geradora de pesquisas voltadas para os setores prioritários da PITCE. Com exceção da UFMG, que consegue trabalhar de forma plural em diversas áreas de pesquisa, nota-se que a especialização existente em algumas das universidades mineiras favorece ao desenvolvimento de pesquisas em áreas específicas. Este o caso da UFV, uma instituição tradicionalmente focada em Ciências Agrárias, que concentra pesquisadores principalmente em biotecnologia e biomassa, com 34\% e $46 \%$ dos pesquisadores dessas áreas estratégicas (Tabela 6).

Podem ser citadas também a Unifal, que se destaca nas pesquisas na área da saúde, principalmente em fármacos, e a Unifei, tradicionalmente voltada para as pesquisas de Engenharia, onde sobressaem aquelas realizadas na área de TI, mais especificamente software e semicondutores.

TABELA 6

Distribuição dos pesquisadores nas áreas estratégicas, por instituições de ensino superior federais Estado de Minas Gerais - 2008

\begin{tabular}{|c|c|c|c|c|c|c|c|c|c|c|c|c|c|}
\hline Áreas & 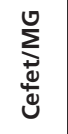 & $\underset{\underline{E}}{\stackrel{U}{E}}$ & 告 & $\frac{\frac{\pi}{4}}{5}$ & 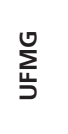 & $\frac{}{\frac{0}{0}}$ & 苂 & 름 & 咅 & 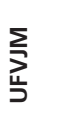 & $\begin{array}{l}\bar{\pi} \\
\stackrel{0}{5} \\
5\end{array}$ & 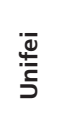 & $\begin{array}{l}\text { त्ञ } \\
\text { 。 }\end{array}$ \\
\hline $\begin{array}{l}\text { Bio- } \\
\text { massa }\end{array}$ & - & - & - & 20,0 & 6,0 & - & 11,0 & 2,0 & 46,0 & 8,0 & - & 7,0 & 100,0 \\
\hline $\begin{array}{l}\text { Biotec- } \\
\text { nologia }\end{array}$ & - & 2,0 & 4,0 & 11,0 & 28,0 & 1,0 & 7,0 & 6,0 & 34,0 & 4,0 & 2,0 & 1,0 & 100,0 \\
\hline $\begin{array}{l}\text { Fárma- } \\
\text { cos }\end{array}$ & 2,0 & - & 20,0 & - & 52,0 & 6,0 & 1,0 & 5,0 & - & - & 13,0 & 1,0 & 100,0 \\
\hline $\begin{array}{l}\text { Nano- } \\
\text { tecnolo- } \\
\text { gia }\end{array}$ & 2,0 & - & 8,0 & - & 32,0 & 5,0 & 3,0 & 29,0 & 18,0 & - & 3,0 & - & 100,0 \\
\hline $\begin{array}{l}\text { Semi- } \\
\text { condu- } \\
\text { tores }\end{array}$ & - & - & 2,0 & - & 37,0 & 7,0 & 10,0 & 23,0 & 7,0 & - & - & 16,0 & 100,0 \\
\hline $\begin{array}{l}\text { Soft- } \\
\text { ware }\end{array}$ & 12,0 & - & 5,0 & 10,0 & 34,0 & - & - & 1,0 & 19,0 & - & 2,0 & 17,0 & 100,0 \\
\hline
\end{tabular}

Fonte: Plano tabular do Diretório de Grupos de Pesquisa do CNPq, Censo 2008. Elaboração dos autores. Nota: As demais IES federais não apresentaram nenhum grupo em área estratégica cadastrado.

Pode-se ainda fazer outro recorte analítico para verificar qual área estratégica se destaca em cada IES federal de Minas, no que se refere ao número de pesquisadores (Tabela 7). Verifica-se, por exemplo, que 36\% dos pesquisadores em áreas estratégicas, 
na UFMG, encontram-se lotados em pesquisas relacionadas a fármacos. Observase, também, que a UFMG e a UFFU são as únicas que possuem pesquisadores em todas as áreas estratégicas em sentido amplo.

TABELA 7

Distribuição dos pesquisadores nas instituições de ensino superior federais, segundo áreas estratégicas de pesquisa

Estado de Minas Gerais - 2008

\begin{tabular}{|c|c|c|c|c|c|c|c|c|c|c|c|c|}
\hline Áreas & 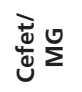 & $\sum_{\underline{E}}^{\underline{E}}$ & 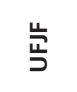 & $\frac{\pi}{\frac{\pi}{5}}$ & 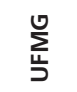 & 은 & 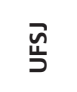 & 림 & 咅 & $\sum_{\substack{3 \\
J}}$ & $\begin{array}{l}\overline{0} \\
.5 \\
5\end{array}$ & 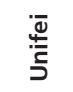 \\
\hline Biomassa & - & - & - & 29,0 & 2,0 & - & 23,0 & 3,0 & 23,0 & 40,0 & - & 14,0 \\
\hline $\begin{array}{l}\text { Biotecno- } \\
\text { logia }\end{array}$ & - & 100,0 & 18,0 & 51,0 & 28,0 & 13,0 & 46,0 & 23,0 & 54,0 & 60,0 & 14,0 & 4,0 \\
\hline Fármacos & 22,0 & - & 62,0 & - & 36,0 & 48,0 & 5,0 & 15,0 & - & - & 73,0 & 4,0 \\
\hline $\begin{array}{l}\text { Nanotec- } \\
\text { nologia }\end{array}$ & 7,0 & - & 8,0 & - & 8,0 & 13,0 & 5,0 & 29,0 & 7,0 & - & 6,0 & - \\
\hline $\begin{array}{l}\text { Semicon- } \\
\text { dutores }\end{array}$ & - & - & 3,0 & - & 11,0 & 25,0 & 20,0 & 29,0 & 3,0 & - & - & 31,0 \\
\hline Software & 72,0 & - & 9,0 & 20,0 & 15,0 & - & - & 1,0 & 13,0 & - & 8,0 & 47,0 \\
\hline Total & 100,0 & 100,0 & 100,0 & 100,0 & 100,0 & 100,0 & 100,0 & 100,0 & 100,0 & 100,0 & 100 & 100,0 \\
\hline
\end{tabular}

Fonte: Plano tabular do Diretório de Grupos de Pesquisa do CNPq, Censo 2008. Elaboração dos autores. Nota: As demais IES federais não apresentaram nenhum grupo em área estratégica cadastrado.

No que se refere à produção científica das IES federais de Minas, uma boa proxy é a publicação de artigos científicos em cada área de conhecimento. ${ }^{15}$ Os dados da Tabela 8 mostram que, não surpreendentemente, a UFMG apresenta o maior número de artigos, em todas as áreas de conhecimento, com exceção das Ciências Agrárias, em que UFV e UFLA estão na frente.

15 Estamos cientes das limitações dessa proxy. Como estamos trabalhando com setores estratégicos, seria interessante analisar o volume de produção nas áreas de software, fármacos, biotecnologia, biomassa, nanotecnologia e semicondutores, definidas aqui como estratégicas, no entanto, é impossível identificar dentro de cada grande área do conhecimento, a partir do Diretório dos Grupos de Pesquisa do CNPq, se a produção científica relaciona-se a uma ou outra área estratégica. 
TABELA 8

Distribuição de artigos completos publicados em periódicos especializados, por grandes áreas de pesquisa, segundo instituições de ensino superior federais Estado de Minas Gerais - 2005-2008

\begin{tabular}{|c|c|c|c|c|c|c|c|c|}
\hline & & & & & & & Em & porcentager \\
\hline $\begin{array}{c}\text { IES } \\
\text { federais }\end{array}$ & $\begin{array}{l}\text { Ciências } \\
\text { Agrárias }\end{array}$ & $\begin{array}{c}\text { Ciências } \\
\text { Exatas e } \\
\text { da Terra }\end{array}$ & $\underset{\text { nharias }}{\text { E n g e - }}$ & $\begin{array}{l}\text { Ciências } \\
\text { da Saúde }\end{array}$ & $\begin{array}{l}\text { Ciências } \\
\text { Biológicas }\end{array}$ & $\begin{array}{l}\text { Ciências } \\
\text { Sociais } \\
\text { Aplicadas }\end{array}$ & $\begin{array}{l}\text { Ciências } \\
\text { Humanas }\end{array}$ & $\begin{array}{l}\text { Linguís- } \\
\text { tica, Le- } \\
\text { tras e } \\
\text { Artes }\end{array}$ \\
\hline Cefet/MG & 0,1 & 0,6 & 3,3 & - & - & - & 3,5 & 1,5 \\
\hline IFMG & 0,2 & - & 0,1 & - & - & - & - & - \\
\hline IFN/MG & 0,2 & - & - & - & - & - & 0,3 & - \\
\hline IFT/MG & 0,8 & - & - & - & - & 0,1 & 0,0 & - \\
\hline UFJF & - & 9,7 & 5,6 & 7,3 & 6,5 & 11,8 & 16,8 & 6,7 \\
\hline Ufla & 23,3 & 5,5 & 1,2 & 1,7 & 5,1 & 7,7 & - & - \\
\hline UFMG & 13,5 & 44,5 & 49,6 & 61,9 & 47,0 & 44,1 & 40,8 & 69,2 \\
\hline Ufop & - & 3,7 & 6,8 & 3,0 & 5,1 & 2,1 & 3,9 & 2,9 \\
\hline UFSJ & - & 2,1 & 3,2 & 0,3 & 1,3 & 1,2 & 6,2 & 2,3 \\
\hline UFTM & - & 0,5 & - & 8,1 & 2,4 & - & 0,5 & 2,2 \\
\hline UFU & 4,9 & 8,8 & 11,5 & 7,8 & 15,6 & 8,0 & 20,9 & 9,2 \\
\hline UFV & 53,1 & 16,9 & 11,6 & 5,2 & 14,5 & 23,7 & 5,8 & 5,9 \\
\hline UFVJM & 3,6 & 2,4 & - & 2,4 & 1,0 & 0,1 & - & - \\
\hline Unifal & 0,1 & 3,1 & 0,2 & 2,1 & 1,5 & - & 0,4 & - \\
\hline Unifei & 0,1 & 2,2 & 7,0 & - & - & 1,1 & 0,9 & - \\
\hline Total & 100,0 & 100,0 & 100,0 & 100,0 & 100,0 & 100,0 & 100,0 & 100,0 \\
\hline
\end{tabular}

Fonte: Plano Tabular do Diretório de Grupos de Pesquisa do CNPq, Censo 2008. Elaboração dos autores.

Observa-se também que, embora a tradição de determinada IES em uma área de conhecimento específica favoreça, a concentração dos grupos de pesquisa em tal área, isso não se reflete necessariamente sobre a produção científica dessas instituições. Se a tradição e a especialização da UFV e da Ufla em Ciências Agrárias se refletem nas suas publicações, o mesmo não ocorre na Unifal, que possui especialização em Ciências da Saúde.

Também chama a atenção o fato de que, na UFJF, a maior parcela de artigos publicados refere-se a assuntos voltados para as áreas de Ciências Sociais Aplicadas e Ciências Humanas, nas quais não estão inseridas pesquisas de setores tecnologicamente estratégicos.

Nas próximas subseções, serão analisadas as congruências das áreas estratégicas com as grandes áreas de conhecimento nas IES federais de Minas Gerais. O objetivo é apresentar não um panorama da evolução brasileira em cada área, mas 
sim um retrato das IES federais de Minas Gerais nos quesitos grupos de pesquisa e pesquisadores nessas áreas (biotecnologia, fármacos, software, semicondutores, nanotecnologia e biomassa).

\subsubsection{Biotecnologia}

As áreas de biotecnologia, nanotecnologia e biomassa possuem potencial de mudar radicalmente processos e produtos (SALERNO, 2004), daí a importância do fomento ao desenvolvimento científico nesse campo.

O Estado de Minas Gerais apresenta historicamente fatores que propiciam o desenvolvimento e a concentração geográfica de atividades relacionada à bioindústria (MARCOLIN, 2004). As escolas de bioquímica, farmácia e medicina de Minas estão entre as primeiras a serem fundadas no país (MARCOLIN, 2004). Na região metropolitana de Belo Horizonte, houve uma concentração espacial de micro, pequenas e médias empresas com foco em saúde humana e biotecnologia, devido a um conjunto de elementos locais, como a expertise e capacitação das universidades e centro de pesquisa, que se juntaram a visões empreendedoras pioneiras (JUDICE, 2006). Em razão dessas características e da forte especialização em biotecnologia na região metropolitana, chegou-se a caracterizá-la como um Arranjo Produtivo Local do setor, com forte atuação da UFMG (CASSIOLATO; LASTRES, 2000; LEMOS, 2000).

A área de biotecnologia apresenta, em Minas Gerais, 81 grupos de pesquisa registrados no CNPq, dos quais 54 (66\%) encontram-se nas IES federais. Analisando as grandes áreas de conhecimento, constata-se que 52\% desses grupos de pesquisa voltados à área de biotecnologia estão nas Ciências Agrárias (28 grupos) e, dentro dessa grande área, a pesquisa se concentra na Medicina Veterinária, com quase $40 \%$ desses grupos (Gráfico 5). No entanto, a pesquisa em biotecnologia também ocorre nas Ciências Biológicas, ${ }^{16}$ com destaque para a Microbiologia, Bioquímica e Genética (Tabela 1 do Anexo).

16 A grande área do conhecimento denominada Ciências Biológicas, de acordo com a Coordenação de Aperfeiçoamento de Pessoal de Nível Superior (Capes), compreende as seguintes áreas de estudo: oceonografia; biologia geral; genética; botânica; zoologia; morfologia; fisiologia; bioquímica; biofísica; farmacologia; imunologia; microbiologia; parasitologia; e ecologia. 


\section{GRÁFICO 5}

Distribuição dos grupos de pesquisa em biotecnologia cadastrados no diretório do CNPq, por grandes áreas do conhecimento

Estado de Minas Gerais - 2008

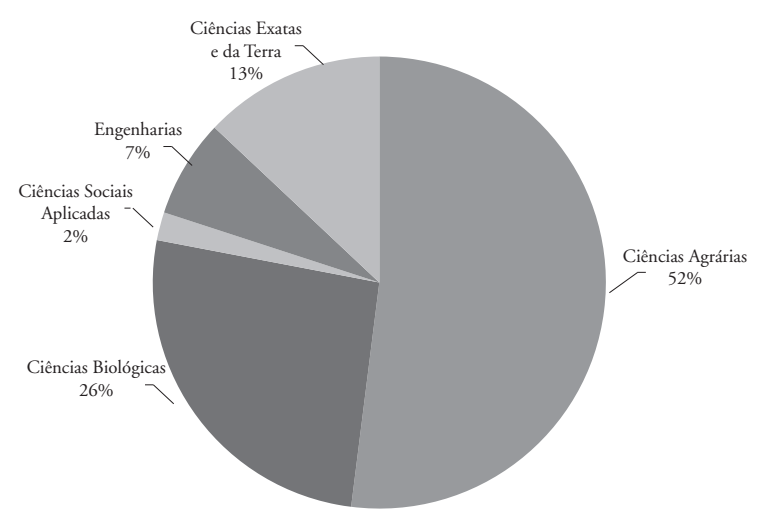

Fonte: Plano Tabular do Diretório de Grupos de Pesquisa do CNPq, Censo 2008. Elaboração dos autores.

No que se refere à distribuição espacial dos grupos de pesquisa na área de biotecnologia, verifica-se que 60\% encontram-se na UFMG e na UFV, ambas com 16 grupos cada, sendo que a maior concentração de pesquisadores nessa área ocorre na UFV (34\%) e na UFMG (28\% do total das IES federais mineiras) (Tabela 6).

\subsubsection{Fármacos}

A indústria farmacêutica brasileira pode ser considerada formuladora/embaladora, pouco participando na fabricação dos princípios ativos (SALERNO, 2004), daí a importância de incentivos em pesquisa universitária de base e P\&D em âmbito laboratorial das empresas. A área de estudos sobre fármacos apresenta, em Minas Gerais, 51 grupos de pesquisa registrados no CNPq, dos quais 47 (92\%) encontram-se nas IES federais. Segundo as grandes áreas de conhecimento, observa-se que $43 \%$ desses grupos de pesquisa voltados ao estudo de fármacos estão inseridos nas pesquisas de Ciências Exatas e da Terra (20 grupos) e, dentro dessa grande área, a pesquisa se concentra na Química, com 90\% desses grupos (Gráfico 6). No entanto, a pesquisa sobre fármacos ocorre também nas Ciências da Saúde e Ciências Biológicas (Tabela 2 do Anexo). 


\section{GRÁFICO 6}

Distribuição dos grupos de pesquisa em fármacos cadastrados no diretório do CNPq, por grandes áreas do conhecimento Estado de Minas Gerais - 2008

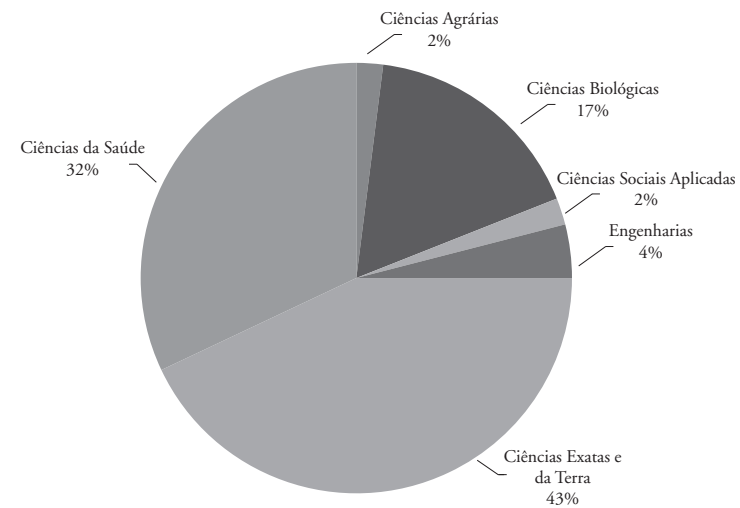

Fonte: Plano Tabular do Diretório de Grupos de Pesquisa do CNPq, Censo 2008. Elaboração dos autores.

No que se refere à distribuição espacial dos grupos de pesquisa na área de fármacos, verifica-se que $44 \%$ encontram-se na UFMG, com 21 grupos de pesquisa nessa área (Tabela 2 do Anexo). Os pesquisadores estão alocados, em sua maioria, na UFMG (52\%), seguida pela UFJF e Unifal (Tabela 6). A UFMG se destaca nessa área, a qual concentra $36 \%$ dos pesquisadores em áreas estratégicas dessa instituição (Tabela 7). Outras instituições apresentam grandes esforços de alocação de recursos humanos nessa área, como a Unifal, com $73 \%$ dos pesquisadores em áreas estratégicas voltados para os fármacos, a UFJF, com 62\%, e a Ufop, com $48 \%$ (Tabela 7). Conclui-se, portanto, que a área de fármacos é a área estratégica em sentido amplo definida pela PITCE, com o segundo maior volume de pesquisadores, representando $23 \%$ do total Gráfico 3).

\subsubsection{Software}

A participação do software brasileiro no mercado internacional é pequena e ainda não possui imagem formada no exterior, no entanto, é o segmento que mais cresce no setor de tecnologia da informação (SALERNO, 2004).

Belo Horizonte possui potencial para sua consolidação como polo de tecnologia de informação no Estado de Minas Gerais. Além da concentração de empresas do setor, a presença da UFMG atuando não apenas no sentido de formar profissionais 
altamente qualificados, mas também como fonte geradora de tecnologias avançadas, é fonte de vantagem competitiva para o desenvolvimento desse polo (VIEIRA et al., 2007). No entanto, ainda exista limitação das relações universidades-empresas do município, o que incide de forma negativa sobre o dinamismo tecnológico das últimas, comprometendo possivelmente objetivos de consolidação de um papel de liderança no mercado (VIEIRA et al., 2007).

Em Minas Gerais, existem 44 grupos de pesquisa registrados no CNPq na área de desenvolvimento de software, dos quais 34 (77\%) encontram-se nas IES federais. Analisando as grandes áreas de conhecimento, constata-se que $50 \%$ desses grupos de pesquisa voltados ao desenvolvimento de software estão nas Ciências Exatas e da Terra (17 grupos) e, dentro dessa grande área, a pesquisa concentrase na Ciência da Computação, sendo essa a área que concentra maior número de pesquisadores (37\% do total) (Gráfico 7). No entanto, o desenvolvimento de software também ocorre nas Engenharias, com destaque para a Engenharia Elétrica (Tabela 3 do Anexo).

\section{GRÁFICO 7}

Grupos de pesquisa em software cadastrados no diretório do CNPq, por grandes áreas do conhecimento

Estado de Minas Gerais - 2008

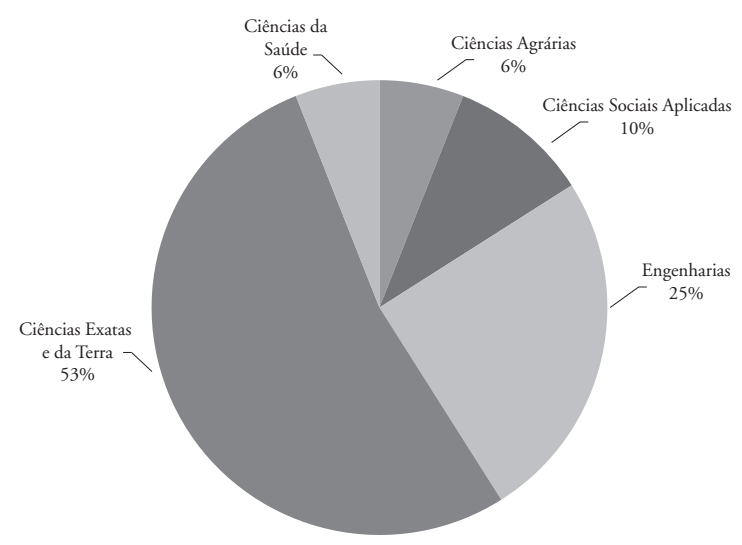

Fonte: Plano Tabular do Diretório de Grupos de Pesquisa do CNPq, Censo 2008. Elaboração dos autores.

No que se refere à distribuição espacial dos grupos de pesquisa em desenvolvimento de software, verifica-se que $26 \%$ encontram-se alocados na UFMG, $18 \%$ na Unifei e $15 \%$ na UFV. Essas três universidades concentram 66\% dos pesquisadores 
mineiros na área de desenvolvimento de software, de um total de 300 pesquisadores registrados no CNPq, com 34\% na UFMG (95 pesquisadores), 19\% na UFV (56) e $16 \%$ na Unifei (com 47) (Tabela 6).

\subsubsection{Demais áreas estratégicas}

A área de estudos sobre biomassa apresenta, em Minas Gerais, 28 grupos de pesquisa registrados no CNPq, dos quais 26 (92\%) encontram-se nas IES federais. Analisando as grandes áreas de conhecimento, constata-se que $46 \%$ desses grupos de pesquisa voltados ao estudo de biomassa estão nas Ciências Agrárias (12 grupos) e, dentro dessa grande área, a pesquisa se concentra na Engenharia Florestal/Recursos Florestais, com $58 \%$ desses grupos. No entanto, a pesquisa em biomassa também ocorre nas Engenharias e Ciências Biológicas (Tabela 4 do Anexo).

No que se refere à distribuição espacial dos grupos de pesquisa na área de biomassa, verifica-se que $60 \%$ estão na UFMG e na UFV, ambas com 16 grupos cada. Já levando em consideração a alocação de pesquisadores, observa-se que 46\% encontram-se na UFV e $20 \%$ na Ufla. A UFMG, apesar de ter 30\% dos grupos das IES federais mineiras em áreas estratégicas, ocupa o quarto lugar quanto ao número de pesquisadores alocados em pesquisas voltadas para biomassa, com $6 \%$ dos pesquisadores mineiros nesta área (Tabela 6).

$\mathrm{Na}$ área de estudos sobre nanotecnologia existem, em Minas Gerais, 24 grupos de pesquisa registrados no CNPq, dos quais 20 (83\%) encontram-se nas IES federais. Analisando as grandes áreas de conhecimento, constata-se que 55\% desses grupos de pesquisa voltados ao estudo da nanotecnologia estão inseridos nas pesquisas de Ciências Exatas e da Terra (11 grupos) e, dentro dessa grande área, a pesquisa se concentra na Física, com $54 \%$ desses grupos. No entanto, a pesquisa em nanotecnologia também ocorre nas Engenharias e Ciências Biológicas (Tabela 5 do Anexo). No que se refere à distribuição espacial dos grupos de pesquisa na área de nanotecnologia, verifica-se que 35\% encontram-se na UFMG e 30\% na UFU. Entre os pesquisadores registrados, 32\% estão alocados na UFMG e 29\% na UFU (Tabela 6).

Segundo Salerno (2004), os semicondutores apresentam forte crescimento e permeiam inúmeras atividades. Nessa área de estudos, em Minas Gerais, há 26 grupos de pesquisa registrados no $\mathrm{CNPq}$, todos alocados nas IES federais. Analisando as grandes áreas de conhecimento, constata-se que $88 \%$ desses grupos de pesquisa voltados ao estudo de semicondutores estão nas Ciências Exatas e da Terra (23 
grupos) e, dentro dessa grande área, a pesquisa se concentra na Física, com 73\% desses grupos, enquanto nas Engenharias este tipo de estudo apresenta a menor expressão (Tabela 6 do Anexo). No que se refere à distribuição espacial dos grupos de pesquisa na área de semicondutores, verifica-se que 34\% encontram-se na UFMG e $30 \%$ na UFU. Entre os pesquisadores cadastrados, 37\% encontram-se na UFMG e $23 \%$ na UFU (Tabela 6).

\section{Considerações finais}

Sabe-se, pela experiência internacional, que o fortalecimento da estrutura de Ciência \& Tecnologia $(\mathrm{C} \& \mathrm{~T})$ passa pela formação de mão de obra qualificada para atuar em setores estratégicos, bem como pelo incentivo ao direcionamento das pesquisas realizadas pelas universidades públicas para áreas prioritárias ao desenvolvimento dos países.

Ressaltando a importância das universidades para os SI, este artigo procurou investigar a relação das pesquisas desenvolvidas pelas universidades federais com as áreas prioritárias da PITCE. A opção por delimitar o foco da análise ao Estado de Minas Gerais deve-se, entre outros fatores, à sua concentração de universidades federais, em relação ao restante do país.

Por todo o exposto, entende-se que Minas Gerais pode desempenhar papel estratégico no direcionamento das políticas de C\&T do governo federal.

As IES federais mineiras possuem pesquisas alinhadas com os setores prioritários da PITCE, destacando-se especialmente nas áreas de biotecnologia, fármacos e software. No caso de biotecnologia e software, há evidências na literatura que indicam a existência de clusters de ambos os setores na região metropolitana de Belo Horizonte. Conforme observado neste trabalho, a UFMG tem papel fundamental na composição destes conglomerados, não apenas formando mão de obra altamente qualificada, mas também desenvolvendo pesquisas em linha com as demandas do avanço tecnológico.

Ainda em relação à área de software, é possível encontrar exemplos de sucesso no transbordamento das pesquisas acadêmicas para o setor produtivo, como o caso da Akwan, start up nascida no Departamento de Ciência da Computação da UFMG e adquirida pela Google (DESTSCHER et al., 2005).

As pesquisas voltadas para a área de fármacos são as que alocam maior número de pesquisadores entre as IES federais mineiras. Ressalta-se, neste contexto, a UFMG, possui pesquisadores alocados em grupos de pesquisas voltados para todos os setores 
estratégicos da PITCE, com destaque para biotecnologia, fármacos, software e semicondutores. Em menor volume, mas também com pesquisas em todos os setores tecnologicamente estratégicos para o país, tem-se a UFU, com pesquisadores alocados principalmente em nanotecnologia, semicondutores e biotecnologia.

Corroborando estudo realizado por Chiarini et al. (2010), observa-se que a UFMG apresenta alto volume de pesquisas e pluralidade das mesmas, constituindose como líder na produção de conhecimento científico entre as IES mineiras. Com exceção da área de Ciências Agrárias, em que a maior parcela de artigos científicos publicados é da UFV, seguida pela Ufla, a UFMG lidera a produção científica em todas as demais áreas de conhecimento.

A tradição das IES em determinadas áreas de conhecimento favorece a concentração de grupos de pesquisa em áreas específicas, como ocorre na UFV, Ufla, Unifei e Unifal.

$\mathrm{Na}$ Ufla e UFV, a concentração de pesquisas em Ciências Agrárias, na qual ambas possuem tradição, reflete-se em suas produções científicas nesta área, que superam a da UFMG. O mesmo ocorre na Unifei, que, embora com volume reduzido de produção de conhecimento técnico-científico (medido pela quantidade de artigos científicos publicados em revistas especializadas nacionais e internacionais), apresenta-se em segundo lugar em produção de conhecimento científico na área de Engenharia, atrás apenas da UFMG.

Entretanto tal efeito positivo da concentração das pesquisas em áreas específicas não fica tão claro quando se observa a Unifal, por exemplo. A universidade concentra suas pesquisas principalmente na área de fármacos, entretanto suas publicações nas áreas de Saúde e Ciências Biológicas ficam bastante aquém do esperado para uma instituição com a sua tradição.

Ocorre que, mesmo em casos de clusters reconhecidos, como os da região de Belo Horizonte, o desenvolvimento de projetos conjuntos de pesquisas entre as universidades e as empresas esbarra em uma série de dificuldades relacionadas às culturas conflitantes da academia e do mercado, além de burocracia e até mesmo desinformação por parte de muitos empresários. Pelo lado acadêmico, muitas vezes o problema fica na dificuldade dos cientistas em realizarem a gestão de seus projetos de forma a transformá-los em empresas de sucesso.

Por fim, o que se buscou, com a análise proposta no artigo, foi mostrar que, embora haja certa congruência de pesquisas nas IES federais de Minas Gerais com as áreas estratégicas em sentido amplo definidas pela PITCE, existe ainda espaço de manobra de políticas públicas que incentivem mais esforços nessas áreas, no sentido 
de criar mecanismos direcionadores de recursos (humanos e financeiros) para o desenvolvimento de pesquisas e áreas prioritárias à capacitação científica e tecnológica do Brasil. Acredita-se que há ainda muitas lacunas a serem preenchidas na literatura nacional, no que tange à investigação da atuação das universidades públicas no SI brasileiro e sua adequação aos setores estratégicos ao desenvolvimento. Podem ser citados, como exemplos, o financiamento às pesquisas, o transbordamento destas para o setor produtivo e a gestão das parcerias universidade-empresa.

\section{Referências bibliográficas}

ALBUQUERQUE, E. M. Sistema Nacional de Inovação no Brasil: uma análise introdutória a partir de dados disponíveis sobre a Ciência e a Tecnologia. Revista de Economia Politica, São Paulo, v. 16, n. 3, p. 56-72, 1996.

. Produção científica E Sistema Nacional de Inovação. Ensaios FEE, Porto Alegre, v. 19, n. 1, p. 156-180, 1998.

ALBUQUERQUE, E. M.; SILVA. L. A.; RAPINI, M. S.; SOUZA, S. G. A. Interactions between firms and universities in an immature system of innovations: a survey of industrial R\&D-performers firms in Minas Gerais. Brazil. UFMG/Cedeplar, 2005 (Texto para discussão, 280).

ALBUQUERQUE, E. M.; SILVA, L. A.; PÓVOA, L. M. C. Diferenciação intersetorial na interação entre empresas e universidades no Brasil. São Paulo em Perspectiva, São Paulo, v. 19, n. 1, p. 95-104, 2005.

BALBACHEVSKY, E. Recursos humanos em áreas estratégicas para inovação: a experiência internacional. Formação de recursos humanos em áreas estratégicas de Ciência, Tecnologia e Inovação. Brasília: Centro de Gestão e Estudos Estratégicos, 2010.

BALDINI, J. P.; BORGONHONI, P. As relaçôes universidade-empresa no Brasil: surgimento e tipologias. Caderno de Administração, v. 15, n. 2, p. 29-38, jul./dez. 2007.

CAMPANÁRIO, M. A.; SILVA, M. M.; COSTA; T. R. Política Industrial, Tecnológica e de Comércio Exterior (PITCE): análise de fundamentos e arranjos institucionais. In: XI SEMINÁRIO LATINO-IBEROAMERICANO DE GESTIÓN TECNOLOGICA. Salvador, 2005.

CASSIOLATO, J. E.; LASTRES, H. M. M. Local Systems of Innovation in Mercosur Countries. Industry and Innovation, v. 7, n. 1, p. 33-54, 2000. 
CHIARINI, T.; VIEIRA, K. P.; ZORZIN, P. L. Produção de pesquisa científica e de conhecimento: um retrato da atual distribuição de recursos entre as universidades federais mineiras. In: XIV SEMINÁRIO SOBRE A ECONOMIA MINEIRA. 2010. Anais economia mineira. Diamantina, 2010.

CHIARINI, T.; VIEIRA, K. P.; ZORZIN, P. L. Universidades federais mineiras: análise da produção de pesquisa científica e conhecimento no contexto do sistema mineiro de inovação. Revista Nova Economia, UFMG, no prelo.

CRUZ, C. H. B. A Universidade, a empresa e a pesquisa. In: SEMINÁRIO BRASIL EM DESENVOLVIMENTO DA UNIVERSIDADE FEDERAL DO RIO DE JANEIRO (UFRJ). Rio de Janeiro, 2004. Disponível em: <http://www.ifi.unicamp.br/-brito/artigos/ univ-empr-pesq-rev102003b.pdf>. Acesso em: 28 jan. 2010.

DAGNINO, R.; GOMES, E. J. A relação universidade-empresa: comentários sobre um caso atípico. Gestão e Produção, v. 10, n. 3, p. 283-292, dez. 2003.

DAGNINO, R. A relação universidade-empresa no Brasil e o "argumento da Hélice Tripla". Revista Brasileira de Inovação, v. 2, n. 02, p. 267-307, jul./dez. 2003.

DEUTSCHER, J A.; RENAULT, T.; ZIVIANI, N. A geraçāo de riqueza a partir da universidade: o caso da Akwan. Belo Horizonte: Departamento de Ciência da Computação da UFMG, 2005.

DOSI, G. Technological paradigms and technological trajectories. Research Policy, v. 11, n. 3, p. 147-162, 1982.

ESTEVES, L. A.; MEIRELLES. J. G. P. Innovation and cooperation between firms and universities: evidence from Brazil. In: THIRD CONFERENCE ON MICRO EVIDENCE ON INNOVATION AND DEVELOPMENT - MEIDE. Rio de Janeiro, 2009.

GOMES, E. J. A relação universidade-empresa no Brasil: testando hipóteses a partir do caso da Unicamp. Tese (Doutorado). Campinas, Programa de Pós-graduação em Política Científica e Tecnológica do Instituto de Geociências da Universidade Estadual de Campinas - Unicamp, 2001.

HAGEDOORN, J.; LINK, A. N.; VONORTAS, N. S. Research partnerships. Research Policy, n. 29, p. 567-586, 2000.

JUDICE, V. Competências em internacionalização e inovação em biotecnologia no Brasil. Journal of Technology Mangemment \& Innovation, Santiago, JOTMI Research Group, ano 1, n. 4, 2006. 
KUPFER, D. Uma abordagem neo-schumpeteriana da competitividade industrial. Ensaios FEE, Porto Alegre, v. 17, n. 1, p. 355-372, 1996.

LEMOS, M. B.. A construção de redes locais de inovação sob condiçôes periféricas: o caso de biotecnologia na aglomeração de Belo Horizonte. Projeto Globalização e Inovação Localizada: experiências e sistemas locais no âmbito do Mercosul e proposições políticas de C\&T. Rio de Janeiro: Instituto de Economia, UFRJ, 2000.

MARCOLIN, N. Da botica a sala de aula. Primeira escola de farmácia foi criada a 165 anos em Ouro Preto. Pesquisa Ciência e Tecnologia no Brasil, São Paulo, Fapesp, n. 97, p.89, mar. 2004.

MARQUES, R. A.; FREITAS, I. M. B.; SILVA, E. M. P. Colaboração com universidade e as atividades para inovação de empresas brasileiras. Engevista, v. 9, n. 2, p. 112-128, dez. 2007.

MELLO, J. M. C.; MACULAN, A. M.; RENAULT, T. Brazilian universities and their contribution to innovation and development. In: GORANSSON, B.; BRUNDENIUS, C. (Orgs.). Developing universities: the changing role of academic institutions in development. Londres: Routledge/IDRC, 2009, p. 1-25.

NADVI, K. Industrial clusters and networks: case studies of SME's growth and innovation. Paper commissioned by The Small and Medium Industries Branch. October 1995.

PEREZ, C.; SOETE, L. Catching up in technology: entry barriers and windows of opportunity. In: DOSI, G. et al. (Eds.). Technical change and economic theory. New York: Pinter Publishers, 1988.

PEREZ, C. New technological model and higher education: a view from the changing world of work. In: OSPINA, G. L. (Org.). Challenges \& options: specific proposals. Caracas: Unesco, 1992.

PITCE - Política Industrial, Tecnológica e de Comércio Exterior. Diretrizes de política industrial, tecnológica e de comércio exterior. Brasília, 2003. Disponível em: <http://www. abdi.com.br/?q=system/files/diretriz_politica_industrial.pdf >. Acesso em: 24 jun. 2010.

POVOA, L. C.; RAPINI, M. S. Technology transfer from universities and public research institutes to firms in Brazil: what is transferred and how the transfer is made. In: XXXVII ENCONTRO NACIONAL DE ECONOMIA. Foz do Iguaçu, 2009.

PRATES, D. M.; CINTRA, M. A. M. A estratégia de desenvolvimento da Índia: da independência aos dilemas da primeira década do século XXI. In: CARDOSO Jr., J. C.; ACIOLY, L.; MATIJASCIC, M.. Trajetórias recentes de desenvolvimento: estudo de experiências internacionais selecionadas. Livro 2. Brasília: Instituto de Pesquisa Aplicada, 2009, p. 379-432. 
RAPINI, M. S.; CAMPOS, B. C. As universidades mineiras e suas interaçôes com a indústria: uma análise a partir de dados do Diretório. In: XI SEMINÁRIO SOBRE A ECONOMIA MINEIRA. 2004. Anais Economia Mineira. Diamantina, 2004.

RAPINI, M. S.; ALBUQUERQUE, E. M.; SILVA, L. ; SOUZA, S. G. A.; RIGHI, H. M.; CRUZ, W. M. S. Spots of interactions: an investigation on the relationship between firms and universities in Minas Gerais. Brasil. UFMG/Cedeplar, 2006 (Texto para discussão, 286).

RAPINI, M. S.Interação universidade-empresa no Brasil: Evidências do Diretório dos Grupos de Pesquisa do CNPq. Estudos Econômicos. Instituto de Pesquisas Econômicas. v. 37. p. 211-233. 2007.

RAPINI, M. S.; RIGHI, H. M. Interação universidade-empresa no Brasil em 2002 e 2004: uma aproximação a partir dos Grupos de Pesquisa do CNPq. Revista Economia, Brasília, v. 8, n. 2, p. 248-268, maio/ago. 2007.

RAPINI, M. S.; SUZIGAN. W.; FERNANDES, R.; CARVALHO, S. S. M.; CHAVES, C. V. A contribuição das universidades e institutos de pesquisa para o sistema de inovação brasileira. In: XXXVII ENCONTRO NACIONAL DE ECONOMIA. Foz do Iguaçu, 2009.

RENAULT, T.; MELLO, J. M. C.; CARVALHO, R. Universities. organizational structure of the research activity and the spin-off formation: lessons from the Brazilian case. In: XXV IASP WORLD CONFERENCE. Joanesburgo, 2008 (CD-ROM).

RIGHI, H. M.; RAPINI, M. S. A evolução da interação entre universidade e empresas em Minas Gerais: uma análise a partir dos Censos 2002 e 2004 do Diretório dos Grupos de Pesquisa do CNPq. In: XII SEMINÁRIO SOBRE A ECONOMIA MINEIRA. Diamantina, 2006.

SALERNO, M. S. A política industrial, tecnológica e de comércio exterior do governo federal. Parcerias Estratégicas, n. 19, dez. 2004.

SUZIGAN, W.; ALBUQUERQUE, E. M. The underestimated role of universities for development: notes on historical roots of Brazilian system of innovation. In: XVth WORLD ECONOMIC HISTORY CONGRESS. Utrecht: International Economic History Association, 2009.

TETHER, B. Who co-operates for innovation, and why: an empirical analysis. Research Policy, n. 31, p. 947-967, 2002.

TEBECHNARI, G. D. N. Mitos, ciclos e a hegemonia da convenção do desenvolvimento no pós-guerra. Leituras de Economia Política, Campinas, n. 15, jan./dez. 2009.

VIEIRA, K. P.; SANTOS, F.; OLIVEIRA, F. H. P. O pólo de tecnologia da informação de Belo Horizonte. Cadernos BDMG, n. 14, p. 1-130, abr. 2007. 
Tulio Chiarini, Karina Pereira Vieira

VILELLA, A. Dos anos dourados de JK à crise não resolvida. In: GIAMBIAGI, F. et al. (Orgs.). Economia brasileira contemporânea. São Paulo: Campus, 2005.

ZAWISLAK, P. A.; DALMARCO, G. University-industry interaction: a knowledge flow typology. In: 18th INTERNATIONAL CONFERENCE ON MANAGEMENT OF TECHNOLOGY. Orlando. Management of Green Technology. Miami: IAMOT, 2009. 


\section{ANEXO}

TABELA 1

Grupos de pesquisa em biotecnologia cadastrados no diretório do CNPq, por instituições de ensino superior federais, segundo grandes áreas do conhecimento e áreas de avaliação

Estado de Minas Gerais - 2010

\begin{tabular}{|c|c|c|c|c|c|c|c|c|c|c|c|c|c|}
\hline $\begin{array}{l}\text { Grandes } \\
\text { áreas do } \\
\text { conheci- } \\
\text { mento }\end{array}$ & $\begin{array}{l}\text { Áreas de } \\
\text { avaliação }\end{array}$ & $\sum_{\underline{E}}^{\stackrel{U}{E}}$ & 崩 & $\frac{\frac{\pi}{4}}{5}$ & 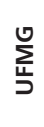 & $\frac{\text { 응 }}{\text { 는 }}$ & 范 & 국 & 竞 & $\sum_{3}^{5}$ & $\begin{array}{l}\frac{\pi}{5} \\
\frac{5}{5}\end{array}$ & 㐫 & 宽 \\
\hline \multirow{5}{*}{$\begin{array}{l}\text { Ciências } \\
\text { Agrárias }\end{array}$} & Agronomia & - & - & 2 & - & - & - & - & 5 & - & - & - & 7 \\
\hline & $\begin{array}{l}\text { Medicina veteri- } \\
\text { nária }\end{array}$ & - & - & 1 & 4 & - & - & 1 & 4 & 1 & - & - & 11 \\
\hline & $\begin{array}{l}\text { Ciência e tec. } \\
\text { dos alimentos }\end{array}$ & - & - & 3 & 1 & - & - & - & 1 & - & - & - & 5 \\
\hline & $\begin{array}{l}\text { Engenharia } \\
\text { florestal }\end{array}$ & - & - & - & - & - & - & - & - & 1 & - & - & 1 \\
\hline & Zootecnia & - & - & 1 & - & - & - & - & 3 & - & - & - & 4 \\
\hline \multirow{2}{*}{$\begin{array}{l}\text { Ciências } \\
\text { Exatas e da } \\
\text { Terra }\end{array}$} & Química & 1 & 1 & - & 1 & - & 2 & - & - & - & - & 1 & 6 \\
\hline & Física & - & - & - & - & - & - & 1 & - & - & - & - & 1 \\
\hline \multirow{4}{*}{ Engenharias } & $\begin{array}{l}\text { Engenharia } \\
\text { biomética }\end{array}$ & - & - & - & 1 & - & - & - & - & - & - & - & 1 \\
\hline & $\begin{array}{l}\text { Engenharia } \\
\text { mecânica }\end{array}$ & - & - & - & 1 & - & - & - & - & - & - & - & 1 \\
\hline & $\begin{array}{l}\text { Eng. materiais e } \\
\text { metalúrgica }\end{array}$ & - & - & - & - & 1 & - & - & - & - & - & - & 1 \\
\hline & $\begin{array}{l}\text { Engenharia } \\
\text { química }\end{array}$ & - & - & - & 1 & - & - & - & - & - & - & - & 1 \\
\hline \multirow{7}{*}{$\begin{array}{l}\text { Ciências } \\
\text { Biológicas }\end{array}$} & Bioquímica & - & - & - & - & - & 1 & 1 & -1 & - & - & - & 3 \\
\hline & Ecologia & - & - & - & - & - & - & - & - & - & 1 & - & 1 \\
\hline & Farmacologia & - & - & - & 1 & - & - & - & - & - & - & - & 1 \\
\hline & Imunologia & - & - & - & 1 & - & - & - & - & - & - & - & 1 \\
\hline & Parasitologia & - & - & - & 1 & - & - & - & - & - & - & - & 1 \\
\hline & Genética & - & 1 & - & 2 & - & - & - & - & - & - & - & 3 \\
\hline & Microbiologia & - & - & - & 2 & - & 1 & - & 1 & - & - & - & 4 \\
\hline $\begin{array}{l}\text { Sociais } \\
\text { Aplicadas }\end{array}$ & Direito & - & - & - & - & - & - & - & 1 & - & - & - & 1 \\
\hline
\end{tabular}

Fonte: Diretório de Grupos de Pesquisa no Brasil - CNPq. Elaboração dos autores.

Nota: Palavras-chave utilizadas na pesquisa: biotecnologia/ bio tecnologia. Data da pesquisa: 14/06/2010.

As demais IES federais não apresentaram nenhum grupo cadastrado. 
Tulio Chiarini, Karina Pereira Vieira

TABELA 2

Grupos de pesquisa em fármacos cadastrados no diretório do CNPq, por instituições de ensino superior federais, segundo grandes áreas do conhecimento e áreas de avaliação Estado de Minas Gerais - 2010

\begin{tabular}{|c|c|c|c|c|c|c|c|c|c|c|c|}
\hline $\begin{array}{l}\text { Grandes } \\
\text { áreas do } \\
\text { conheci- } \\
\text { mento }\end{array}$ & $\begin{array}{l}\text { Áreas de } \\
\text { avaliação }\end{array}$ & 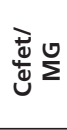 & 䈼 & 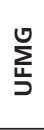 & $\frac{\text { 운 }}{\frac{1}{5}}$ & 茫 & 룩 & 站 & $\begin{array}{l}\bar{\pi} \\
\frac{\pi}{5} \\
5\end{array}$ & 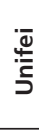 & 䒿 \\
\hline $\begin{array}{l}\text { Ciências } \\
\text { Agrárias }\end{array}$ & $\begin{array}{l}\text { Agrono- } \\
\text { mia }\end{array}$ & - & - & - & - & - & - & 1 & - & - & 1 \\
\hline \multirow{3}{*}{$\begin{array}{l}\text { Ciências } \\
\text { Exatas e } \\
\text { da Terra }\end{array}$} & Química & 2 & 2 & 8 & - & - & 2 & 1 & 2 & 1 & 18 \\
\hline & Física & - & - & - & - & - & - & 1 & - & - & 1 \\
\hline & $\begin{array}{l}\text { Ciência } \\
\text { da com- } \\
\text { putação }\end{array}$ & - & - & 1 & - & - & - & - & - & - & 1 \\
\hline \multirow{2}{*}{$\begin{array}{l}\text { Enge- } \\
\text { nharias }\end{array}$} & $\begin{array}{l}\text { Engen- } \\
\text { haria } \\
\text { Bio- } \\
\text { médica }\end{array}$ & - & - & 1 & - & - & - & - & - & - & 1 \\
\hline & $\begin{array}{l}\text { Eng. } \\
\text { Materiais } \\
\text { e met- } \\
\text { alúrgica }\end{array}$ & - & - & 1 & - & - & - & - & - & - & 1 \\
\hline \multirow{5}{*}{$\begin{array}{l}\text { Ciências } \\
\text { Bioló- } \\
\text { gicas }\end{array}$} & $\begin{array}{l}\text { Bio- } \\
\text { química }\end{array}$ & - & 1 & - & - & 1 & - & - & 1 & - & 3 \\
\hline & Biofísica & - & - & 1 & - & - & - & - & - & - & 1 \\
\hline & $\begin{array}{l}\text { Imuno- } \\
\text { logia }\end{array}$ & - & 1 & - & - & - & - & - & - & - & 1 \\
\hline & $\begin{array}{l}\text { Parasito- } \\
\text { logia }\end{array}$ & - & - & 2 & - & - & - & - & - & - & 2 \\
\hline & Genética & - & - & - & - & - & 1 & - & - & - & 1 \\
\hline \multirow{3}{*}{$\begin{array}{l}\text { Ciência } \\
\text { da } \\
\text { Saúde }\end{array}$} & Farmácia & - & 1 & 6 & 2 & - & - & - & 3 & - & 12 \\
\hline & $\begin{array}{l}\text { Odonto- } \\
\text { logia }\end{array}$ & - & - & 1 & - & - & - & - & 1 & - & 2 \\
\hline & Medicina & - & 1 & - & - & - & - & - & - & - & 1 \\
\hline $\begin{array}{l}\text { Sociais } \\
\text { Aplica- } \\
\text { das }\end{array}$ & Direito & - & - & - & - & - & - & 1 & - & - & 1 \\
\hline
\end{tabular}

Fonte: Diretório de Grupos de Pesquisa no Brasil - CNPq. Elaboração dos autores.

Nota: Palavras-chave utilizadas na pesquisa: fármaco/fármacos. Data da pesquisa: 14/06/2010

As demais IES federais não apresentaram nenhum grupo cadastrado. 
Atividades de pesquisa científica e tecnológica das IES federais de MG e as diretrizes da PITCE

TABELA 3

Grupos de pesquisa em desenvolvimento de software cadastrados no diretório do CNPq, por instituições de ensino superior federais, segundo grandes áreas do conhecimento e áreas de avaliação

Estado de Minas Gerais - 2010

\begin{tabular}{|c|c|c|c|c|c|c|c|c|c|c|c|}
\hline $\begin{array}{l}\text { Grandes } \\
\text { áreas do } \\
\text { conhe- } \\
\text { cimento }\end{array}$ & $\begin{array}{l}\text { Áreas de } \\
\text { avaliação }\end{array}$ & 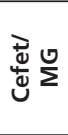 & 訔 & $\frac{\pi}{5}$ & 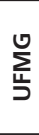 & 응 & 군 & 咅 & $\begin{array}{l}\frac{\pi}{4} \\
\frac{5}{5}\end{array}$ & 离 & 흄 \\
\hline \multirow{2}{*}{$\begin{array}{l}\text { Ciências } \\
\text { Agrárias }\end{array}$} & Agronomia & - & - & - & - & - & - & 1 & - & - & 1 \\
\hline & $\begin{array}{l}\text { Engenharia } \\
\text { Agrícola }\end{array}$ & - & - & 1 & - & - & - & - & - & - & 1 \\
\hline \multirow{3}{*}{$\begin{array}{l}\text { Ciências } \\
\text { Exatas e da } \\
\text { Terra }\end{array}$} & $\begin{array}{l}\text { Astrono- } \\
\text { mia }\end{array}$ & - & - & - & - & - & - & - & - & 1 & 1 \\
\hline & $\begin{array}{l}\text { Ciência da } \\
\text { Computa- } \\
\text { ção }\end{array}$ & 1 & 1 & 3 & 3 & 1 & - & 2 & 1 & 3 & 15 \\
\hline & $\begin{array}{l}\text { Geociên- } \\
\text { cias }\end{array}$ & - & - & - & - & - & - & 1 & - & - & 1 \\
\hline \multirow{4}{*}{ Engenharias } & $\begin{array}{l}\text { Engenharia } \\
\text { elétrica }\end{array}$ & - & - & - & 2 & - & 1 & - & - & 2 & 5 \\
\hline & $\begin{array}{l}\text { Engenharia } \\
\text { de minas }\end{array}$ & - & - & - & 1 & - & - & - & - & - & 1 \\
\hline & $\begin{array}{l}\text { Eng. } \\
\text { materiais } \\
\text { e metalúr- } \\
\text { gica }\end{array}$ & - & - & - & - & 1 & - & - & - & - & 1 \\
\hline & $\begin{array}{l}\text { Engenharia } \\
\text { Civil }\end{array}$ & - & 1 & - & - & - & - & - & - & - & 1 \\
\hline \multirow{2}{*}{$\begin{array}{l}\text { Ciências da } \\
\text { saúde }\end{array}$} & Medicina & - & - & - & 1 & - & - & - & - & - & 1 \\
\hline & $\begin{array}{l}\text { Educação } \\
\text { Física }\end{array}$ & - & - & - & 1 & - & - & - & - & - & 1 \\
\hline $\begin{array}{l}\text { Sociais } \\
\text { Aplicadas }\end{array}$ & Direito & - & - & - & - & - & - & 1 & - & - & 1 \\
\hline $\begin{array}{l}\text { Ciências } \\
\text { Humanas }\end{array}$ & Educação & 2 & - & - & - & 1 & - & - & - & - & 3 \\
\hline $\begin{array}{l}\text { Linguística, } \\
\text { letras e artes }\end{array}$ & Linguística & - & - & - & 1 & - & - & - & - & - & 1 \\
\hline
\end{tabular}

Fonte: Diretório de Grupos de Pesquisa no Brasil - CNPq. Elaboração dos autores. Nota: Palavra-chave utilizada na pesquisa: software. Data da pesquisa: 14/06/2010. As demais IES federais não apresentaram nenhum grupo cadastrado. 
Tulio Chiarini, Karina Pereira Vieira

TABELA 4

Grupos de pesquisa em biomassa cadastrados no diretório do CNPq, por instituições de ensino superior federais, segundo grandes áreas do conhecimento e áreas de avaliação Estado de Minas Gerais - 2010

\begin{tabular}{|c|c|c|c|c|c|c|c|c|}
\hline $\begin{array}{l}\text { Grandes } \\
\text { áreas do } \\
\text { conheci- } \\
\text { mento }\end{array}$ & $\begin{array}{l}\text { Áreas de } \\
\text { avaliação }\end{array}$ & Ufla & UFMG & UFSJ & UFV & UFVJM & Unifei & Total \\
\hline \multirow{3}{*}{$\begin{array}{l}\text { Ciências } \\
\text { Agrárias }\end{array}$} & Agronomia & 1 & - & - & 1 & 1 & - & 3 \\
\hline & $\begin{array}{l}\text { Engenharia } \\
\text { Agrícola }\end{array}$ & - & - & - & 2 & - & - & 2 \\
\hline & $\begin{array}{l}\text { Engenharia } \\
\text { Florestal }\end{array}$ & 3 & - & - & 4 & - & - & 7 \\
\hline $\begin{array}{l}\text { Ciências } \\
\text { Exatas e da } \\
\text { Terra }\end{array}$ & Química & - & 1 & 1 & - & - & - & 2 \\
\hline \multirow{4}{*}{ Engenharias } & $\begin{array}{l}\text { Engenharia } \\
\text { Sanitária }\end{array}$ & 1 & - & - & 1 & - & - & 2 \\
\hline & $\begin{array}{l}\text { Engenharia } \\
\text { Mecânica }\end{array}$ & - & 1 & - & - & - & 2 & 3 \\
\hline & $\begin{array}{l}\text { Engenharia } \\
\text { Elétrica }\end{array}$ & - & 1 & - & - & - & - & 1 \\
\hline & $\begin{array}{l}\text { Engenharia } \\
\text { Química }\end{array}$ & - & 1 & - & - & - & - & 1 \\
\hline \multirow{3}{*}{$\begin{array}{l}\text { Ciências } \\
\text { Biológicas }\end{array}$} & Ecologia & - & - & - & 1 & - & - & 1 \\
\hline & Bioquímica & - & - & 1 & 1 & - & - & 2 \\
\hline & Botânica & - & 1 & - & - & - & - & 1 \\
\hline $\begin{array}{l}\text { Ciência da } \\
\text { Saúde }\end{array}$ & Nutrição & - & - & - & - & 1 & - & 1 \\
\hline
\end{tabular}

Fonte: Diretório de Grupos de Pesquisa no Brasil - CNPq. Elaboração dos autores.

Nota: Palavra-chave utilizada na pesquisa: biomassa. Data da pesquisa: 14/06/2010

As demais IES federais não apresentaram nenhum grupo cadastrado. 
TABELA 5

Grupos de pesquisa em nanotecnologia cadastrados no diretório do CNPq, por instituições de ensino superior federais, segundo grandes áreas do conhecimento e áreas de avaliação Estado de Minas Gerais - 2010

\begin{tabular}{|c|c|c|c|c|c|c|c|c|c|c|}
\hline $\begin{array}{l}\text { Grandes } \\
\text { áreas do } \\
\text { conheci- } \\
\text { mento }\end{array}$ & $\begin{array}{l}\text { Áreas de } \\
\text { avaliação }\end{array}$ & 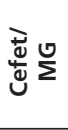 & 告 & 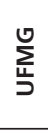 & 윰 & 華 & $\frac{2}{5}$ & 站 & $\begin{array}{l}\frac{\overline{0}}{5} \\
\frac{5}{5}\end{array}$ & 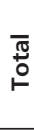 \\
\hline $\begin{array}{l}\text { Ciências } \\
\text { Agrárias }\end{array}$ & $\begin{array}{l}\text { Ciência } \\
\text { e tec. } \\
\text { dos ali- } \\
\text { mentos }\end{array}$ & - & - & - & - & 1 & - & - & - & 1 \\
\hline \multirow{3}{*}{$\begin{array}{l}\text { Ciências } \\
\text { Exatas e } \\
\text { da Terra }\end{array}$} & Química & 1 & - & - & - & - & 2 & - & 1 & 4 \\
\hline & $\begin{array}{l}\text { Ciência } \\
\text { da com- } \\
\text { putação }\end{array}$ & - & 1 & - & - & - & - & - & - & 1 \\
\hline & Física & - & - & 3 & - & - & 3 & - & - & 6 \\
\hline \multirow{3}{*}{$\begin{array}{l}\text { Engen- } \\
\text { harias }\end{array}$} & $\begin{array}{l}\text { Engen- } \\
\text { haria } \\
\text { mecâni- } \\
\text { ca }\end{array}$ & - & - & 1 & - & - & 1 & - & - & 2 \\
\hline & $\begin{array}{l}\text { Engen- } \\
\text { haria } \\
\text { civil }\end{array}$ & - & - & 1 & - & - & - & - & - & 1 \\
\hline & $\begin{array}{l}\text { Eng. } \\
\text { mate- } \\
\text { riais e } \\
\text { metalúr- } \\
\text { gica }\end{array}$ & - & - & - & 1 & - & - & - & - & 1 \\
\hline \multirow{2}{*}{$\begin{array}{l}\text { Ciências } \\
\text { Biológicas }\end{array}$} & Biofísica & - & - & 1 & - & - & - & - & - & 1 \\
\hline & $\begin{array}{l}\text { Micro- } \\
\text { biologia }\end{array}$ & - & - & 1 & - & - & - & - & - & 1 \\
\hline $\begin{array}{l}\text { Sociais } \\
\text { Aplicadas }\end{array}$ & Direito & - & 1 & - & - & - & - & 1 & - & 2 \\
\hline
\end{tabular}

Fonte: Diretório de Grupos de Pesquisa no Brasil - CNPq. Elaboração dos autores.

Nota: Palavras-chave utilizadas na pesquisa: nanotecnologia/nano. Data da pesquisa: 14/06/2010.

As demais IES federais não apresentaram nenhum grupo cadastrado. 
Tulio Chiarini, Karina Pereira Vieira

TABELA 6

Grupos de pesquisa em semicondutores cadastrados no diretório do CNPq, por instituições de ensino superior federais, segundo grandes áreas do conhecimento e áreas de avaliação

Estado de Minas Gerais - 2010

\begin{tabular}{|c|c|c|c|c|c|c|c|c|c|}
\hline $\begin{array}{l}\text { Grandes } \\
\text { áreas do } \\
\text { conheci- } \\
\text { mento }\end{array}$ & $\begin{array}{l}\text { Áreas de } \\
\text { avaliação }\end{array}$ & UFJF & UFMG & Ufop & UFSJ & UFU & UFV & Unifei & Total \\
\hline \multirow{2}{*}{$\begin{array}{l}\text { Ciências } \\
\text { Exatas e da } \\
\text { Terra }\end{array}$} & Química & - & 2 & - & 2 & 2 & - & - & 6 \\
\hline & Física & 1 & 6 & 1 & 1 & 6 & 1 & 1 & 17 \\
\hline \multirow[b]{2}{*}{ Engenharias } & $\begin{array}{l}\text { Engenharia } \\
\text { Elétrica }\end{array}$ & - & 1 & - & - & - & - & 1 & 2 \\
\hline & $\begin{array}{l}\text { Eng. Ma- } \\
\text { teriais e } \\
\text { metalúr- } \\
\text { gica }\end{array}$ & - & - & - & - & - & - & 1 & 1 \\
\hline
\end{tabular}

Fonte: Diretório de Grupos de Pesquisa no Brasil - CNPq. Elaboração dos autores.

Nota: Palavras-chave utilizadas na pesquisa: semicondutor e semicondutores. Data da pesquisa: 14/06/2010.

As demais IES federais não apresentaram nenhum grupo cadastrado.

ENDEREÇOS PARA CORRESPONDENCIA:

Tulio Chiarini - tuliochiarini@yahoo.com.br

Rua Gabriel Baret de Barros, 233, Centro

Pouso Alegre, MG - 37550-000

Karina Pereira Vieira - karina.pvieira@gmail.com

Rua Ouro Branco, 129, apto. 403, Jardim Paulista

São Paulo, SP - 01455-080 